\title{
Follow-up study regarding the medium- term effectiveness of the home-visiting program "Pro Kind" at age 7 years: study protocol for a randomized controlled trial
}

\author{
Sören Kliem ${ }^{1 *}$ (D, Malte Sandner ${ }^{2}$, Anna Lohmann', Susan Sierau ${ }^{3}$, Verena Dähne ${ }^{4}$, Annette M. Klein ${ }^{4}$
} and Tanja Jungmann ${ }^{5}$

\begin{abstract}
Background: Pro Kind is a German adaptation of the US Nurse Family Partnership program. It is an intervention based on home visits targeting first-time mothers from disadvantaged populations. Pro Kind was implemented as a randomized control trial from 2006 to 2012 with $N=755$ first-time mothers (TG $n=394$, CG $n=391$ ). The 7-8-year follow-up aims to assess the mid-term effects of the program.

Methods/design: Mid-term outcomes are being assessed by trained assessors. In a multimethod approach telephone interviews, on-site interviews, observations and developmental tests will be held in order to assess children's and mothers' life satisfaction, mental health, cognitive and social development, parenting behavior, signs of child abuse or neglect as well as the family's socio-economic status. Furthermore, administrative data will be accessed to obtain information regarding the mother's usage of pediatric health care, welfare usage and employment history.

Discussion: Results regarding the mid-term effects of the intervention from the Pro Kind Follow-up will provide a scientific basis for future primary prevention programs as well as help stakeholders legitimizing early childhood investments.
\end{abstract}

Trial registration: German Clinical Trial Registration DRKS-ID, ID: DRKS00007554. Registered on 11 June 2015, updated on 6 October 2017.

Keywords: Home-visiting program, Parenting, Follow-up

\section{Background}

Based on international research findings, home-visiting programs appear to be a promising approach to support psychosocially and/or economically disadvantaged families. Several meta-analyses show that early prevention programs improve parenting skills, reduce child maltreatment and neglect, and have a positive effect on the child's development [1-8]. Although home-visiting programs have a long tradition in Europe [9], the predominant scientific findings stem from the United States (US), especially from the Nurse Family Partnership Program (NFP; [10]). Within

\footnotetext{
* Correspondence: soeren.kliem@kfn.de

${ }^{1}$ Criminological Research Institute of Lower Saxony, Lützerodestr 9, 30161

Hannover, Germany

Full list of author information is available at the end of the article
}

the NFP framework, disadvantaged mothers receive close support already before the birth of their first child. The home visits continue up to the child's second birthday. NFP supports maternal parenting skills relating to the positive support of the child's emotional, cognitive and social development. Furthermore, child neglect, child maltreatment and child abuse are prevented. By reducing the consumption of alcohol and nicotine, NFP promotes the mother's health-related behaviors during pregnancy. In addition, the program encourages mothers (or the parents) to expand their formal and informal networks. Finally, the program aims to enable the families to gain financial autonomy and hence independence from unemployment benefits and welfare. To evaluate the NFP program three randomized controlled trials (RCTs) were conducted in 
1977, 1988 and 1994 in the three different US populations in Elmira, NY; Memphis, TN; and Denver, CO. In numerous articles these RCTs reported positive effects regarding the mothers' health-related behavior during pregnancy, the child's health, parental skills, the socio-emotional and cognitive development of the child, as well as the integration of the mother into the job market or her willingness to take up educational offers. In the long term, better social integration, lower crime rates and improved labor market outcomes were found for children from families who participated in the NFP program [11-30]. According to current estimates (see [31]), approximately 500 child deaths, 4700 abortions, 36,000 cases of partner violence, 90,000 violent crimes by juvenile offenders, 594,000 cases of property crimes or public order disturbances (e.g., vandalism, damage to property), 36,000 prison terms and 41,000 cases of youth substance abuse will have been prevented by NFP in the US by the year 2031. Two independent US research groups conducted comprehensive cost-benefit analyses of NFP. The first analysis, by the Rand Corporation, calculated net returns of US $\$ 2.88$ for every dollar invested - the returns were greater for the highest-risk families, for which they nearly doubled [32]. The second analysis, by the Washington State Institute for Public Policy, estimated a return of over US $\$ 17,000$ for every family [33]. Both evaluations factored in the cost savings across several public sectors over $10-15$ years, including reduced health care, income assistance and child protection spending. Notably, averted public expenditures were greatest for the most disadvantaged mothers and children, which highlights the importance of offering NFP to those at higher risk [34]. In conclusion, the public savings by NFP in the US (as of 2010) are estimated to be approximately US $\$ 1.5$ billion [31].

Trials of NFP have also been conducted outside the US (currently, there are also trial registrations for Canada [35] and France [36]). In the Netherlands, a trial that compared NFP to existing health and social services found that it reduced prenatal smoking, increased breastfeeding, reduced the number of child protection reports as well as the incidence of partner violence [37-39]. In contrast, an RCT in England that compared NFP (called FNP) to usual health and social services did not find any additional benefits for either the children or their mothers [40]. These differences in the findings of US, Dutch, and English trials emphasize the necessity of carrying out RCTs in further countries outside of the US before implementing NFP on a larger scale. Results from RCTs would assess the program's effectiveness as compared to services that are already in place for the target population [41].

\section{NFP in Germany: The "Pro Kind" study}

In Germany, within the framework of the model project Pro Kind, a German adaptation of the NFP program has been scientifically evaluated since 2006 . The core components of the NFP interventions were implemented by the Pro Kind program without changes, including the target group criteria, the specified average number of visits and the average duration of a visit. Furthermore, the structured procedure as well as the support for the home visitors through supervision accord with the US original. Modeled after the NFP program, the home visitors conducted the visits regularly, from pregnancy to the child's second birthday. Diverging from the original program, in the German adaptation home visits were carried out by social workers and state licensed midwives either alone (mainly midwives) or in tandems of a midwife and a social worker (see [42]), whereas in the NFP program exclusively nurses were engaged as home visitors.

\section{Domains addressed in the Pro Kind intervention}

Six focus areas (domains) are addressed while working with the participants in the intervention setting. These domains are generally regarded as the most important risk and protective factors for the prevention of negative pregnancy outcomes, child abuse or neglect, developmental retardation and limited economic independence.

1. Personal health of the mother. Central in this domain is support during pregnancy. Health-related behavior of the expecting mother is addressed such as nutrition, exercise, sleep and rest, as well as oral hygiene. Furthermore, tobacco and alcohol consumption are covered within this domain. Additionally, pregnancy-related physical changes as well as childbirth are discussed.

2. Healthy environment. In this domain the setup of the home environment for parent and child is addressed. Focus aspects are child safety and accident prevention. Toxic or hazardous aspects of the home environment, such as mold and indoor smoking, are also covered.

3. Personal plans for the future. The timing and other considerations of returning to the job or education are the focus of this domain. In this context family planning also plays an important role. Individual preferences, as well as personal strength and weaknesses of the mother, are explored and taken into account for the development of realistic perspectives. Additionally, aspects of everyday personal management, for example, regarding time and money are addressed within this domain.

4. Maternal/ paternal/ parental role. This is the focal domain between birth and the child's second birthday. But even during pregnancy, parents are sensitized to the basic needs of a child as well as child development in utero. Fears and expectations regarding the life with a child are also addressed. 
Post-partum baby care and nutrition as well as basic needs of a newly born are covered. Later developmental and educational aspects (i.e., media exposure), as well as stimulation of the parent-child interaction, are important features of this domain.

5. Social network. Social support from the partner, the parents or friends are aspects in this domain. Building interfamilial relationships and friendships as well as falling back on those for everyday support are supported. On the other hand, resolving conflicts, and appropriate non-violent communication between partners are covered.

6. Utilization of social as well as health services. Aspects from this domain are usually covered in case of acute necessity as well as for establishing a general network of support. Examples are checkups during pregnancy, check-ups for the child or mother-child playgroups or classes. Additionally, mothers are supported in the arrangement or accompanied to official appointments. In cases of psychiatric illness, developmental problems of the child or domestic abuse contact with the relevant social, medical or legal services is facilitated.

\section{Methodological starting point of the Pro Kind project Sample and sampling}

The Pro Kind program was conducted from 2006 to 2012 in the three German states Bremen, Lower Saxony and Saxony (funded by the German Federal Ministry for Family Affairs, Senior Citizens, Woman and Youth BMFSJ [funding code: IIA6-25080820 V6], the Günter-Reimann-Dubbers Foundation [no funding code available], the Dürr Foundation [no funding code available], and the TUI Foundation [no funding code available]; the principal investigator of the intervention phase was $\mathrm{TJ})$. The program was evaluated via longitudinal assessment [43] up to the children's third birthday within the framework of a multicenter RCT. At the time of the baseline survey, $N=755$ first-time mothers (TG $n=394$, CG $n=391$ ) participated, who were 12 to 28 weeks pregnant. In addition to first-time pregnancy the inclusion criteria were a financial risk factor (e.g., receiving welfare benefits or being in debt), as well as at least one further social or personal risk factor (e.g., being under age, lack of a school leaving certificate, having experienced abuse or neglect). In an a priori power analysis before the original RCT the sample size was estimated to be $N=775$. We assumed (1) a minimum detectable effect sizes of $E S=0.20$ (i.e., small effect), (2) a type I error rate (false positive) of $\alpha=.05$, (3) statistical power (1 $-\beta$ ) of .80 (where $\beta$ is the probability of making a Type II error, i.e., failing to detect a true effect if it is present) and (4) an attrition rate of $25 \%$ for this estimation.

The participants were recruited through various multipliers - especially through gynecologists, midwives, youth welfare offices, psychosocial counseling centers, and employment agencies [44]. After admission to the model project, those who at the time were between 12 and 28 weeks pregnant were randomly allocated to either the study group or the control group via a computer program (Efron's biased coin design, strata: implementation location, being under age, and nationality of the mothers). Both groups had access to the regular support offered by the German welfare system and were informed about the latter. Furthermore, travel expenses to medical check-ups during as well as after pregnancy were covered as part of the panel maintenance. In addition, compensation was paid for the time participants invested for the program assessment.

\section{Program participation}

As in the original NFP program, Pro Kind participation was voluntary. It is, hence, evident that not all mothers in the experimental group stayed in the program up to the child's second birthday and hence not all program contents could be covered as intended. In all, $n=166$ (42.2\%) of the $n=394$ randomized mothers in the experimental group dropped out of the intervention prematurely. The reasons for termination can be divided into endogenous and exogenous causes. Endogenous termination causes can be understood as those that were caused deliberately and directly by the mother (e.g., through an explicit demand to terminate the program) or indirectly (e.g., by cutting off contact). Conversely, exogenous termination causes can be understood as those caused by external circumstances (e.g., the child being taken into custody by the youth welfare office, sudden death of the child, relocation of the mother to an area where no further home visits could be provided) and hence not deliberately caused by the mother. During the first intervention phase (before the birth of the child) $n=52$ mothers terminated the program prematurely; hereof, $n=38$ (73.1\%) terminations can be regarded as endogenous terminations. During the second intervention phase (after birth up to the child's first birthday) $n=87$ additional mothers dropped out of the intervention. Of these, $n=48$ (55.2\%) can be regarded as endogenous terminations. During the last intervention phase (from the child's first to second birthday) only 27 more mothers did not complete the program as intended; $n=17(63.0 \%)$ due to endogenous termination causes.

Altogether, the families received an average of $M=32.7$ home visits $(S D=18.6)$ with a range of 0 to 94 home visits. If only those families that completed the program are considered as intended, there was an average of 45.3 home visits $(S D=19.7)$ ranging from 11 to 94 home visits. Across all families, approximately 13,000 home visits were conducted within the Pro Kind project. The average length of a home visit was $82 \mathrm{~min}$. In conclusion, the length of the home visits, as well as the frequency among 
those families that completed the program, are comparable to those of the US original.

\section{Current research results from the home-visiting program Pro Kind}

Data collection at the time points at 6,12 and 24 months after birth of the reference child showed small positive effects of the Pro Kind program on maternal feelings of parental self-efficacy $(\beta=.03$; Wald $=4.05 ; d f=1 ; p=.044)$, social support $(\beta=.04$; Wald $=3.85 ; d f=1 ; p=.050)$ and their knowledge about child-rearing $(\beta=.03$; Wald $=3.43$; $d f=1 ; p=.064$ ) [43]. In addition, fewer women in the treatment group stated that they suffered from depressive mood 24 months after birth (OR 0.54, $p=.070]$. This finding was confirmed by administrative health insurance data that showed that fewer mothers in the treatment group used antidepressants $\left(p=.040^{1}\right)$. The increased maternal wellbeing may be one reason why in the treatment group fewer pregnancy terminations (conditional on a further pregnancy) than in the control group were observed (OR $0.54, p=.090$ ). This might also as a consequence have led to a higher rate of second births 36 months after birth (OR, 1.48, $p=.030$ ). Regarding the children, the intervention resulted in an improvement in the cognitive development of the girls in the treatment group (at 6 months, ES $0.29, p<0.05$; at 12 months, ES $0.28, p<.05$; at 24 months, ES $0.24, p<.01$ ), whereas no improvement could be found in the boys' cognitive skills. One possible explanation for the gender-specific effect could be that the intended treatment, consisting of the parents reading to, and singing with, their children, was implemented more often with female children compared to male children [45-47].

In addition, the model project Pro Kind is being evaluated by encompassing economic research, for which the most important goal was, and is, to conduct a cost-benefit analysis. The costs for providing the home-visiting program were thereby contrasted with the monetized benefits of the intervention, whereby, in conclusion, the program's return on investment (ROI) can be determined. The cost of an average intervention was approximately $€ 8.700$ [48]. Since the home-visiting program Pro Kind seeks to achieve improvements in several different domains, the saving effects should be different in the various domains and concern different fiscal areas.

\section{Methods/design}

The Follow-Up Study Regarding the Medium-Term Effectiveness of the Home-Visiting Program "Pro Kind," Based on a Randomized, Controlled Research Design (official study title: "Follow-Up Untersuchung zur mittelfristigen Wirksamkeit des Hausbesuchsprogramms Pro Kind anhand eines randomisierten kontrollierten Forschungsdesigns, Acronym: Pro Kind Follow-up") is funded by the German Federal Ministry of Education and Research
(BMBF funding codes: 01EL1408A, 01EL1408B, 01EL1408C), So far, it has been possible to reestablish contact with a number of families (as of today, approximately 500 families could be reached, re-recruitment is still ongoing, first family contacted on 15 June 2015) and request participation in a follow-up survey. When the (reference) children are at primary school age (7-9 years), the medium-term effects of the home-visiting program Pro Kind is to be studied with the help of multimethod survey approaches from the perspective of the children as well as the mothers, in addition to administrative data. The study is registered in the German Clinical Trial Register (trial ID: DRKS00007554, date of registration: 11 June 2015). The main sponsor of the Pro Kind Follow-up is the Criminological Research Institute of Lower Saxony (KFN, principal investigator Dr. Sören Kliem). Secondary sponsorship is provided by the University of Rostock (Prof. Dr. Tanja Jungmann) the Institute for Employment Research Nuremberg (IAB, Dr. Malte Sandner) as well as the University Clinic Leipzig (Prof. Kai von Klitzing).

\section{Procedure}

The follow-up study can be subdivided in to six domains (1) interviewer training, (2) assessment of contact details, (3) telephone interviews, (4) on-site interviews and developmental tests, (5) acquisition of administrative data and (6) data analysis. The sponsoring institutions will be involved in these domains as follows: KFN: (1), (2), (3), (4), (5); IAB: (1), (2), (5), (6); University of Leipzig: (1), (4), (6), University of Rostock: (1). An overview of the ProKind Follow-up schedule can be found in Fig. 1. The protocol is reported according to the Standard Protocol Items: Recommendations for Interventional Trials (SPIRIT; Fig. 1 and Additional file 1).

\section{Interviewer training}

All interviewers underwent several days of intensive training as preparation for the home interviews. They received general information regarding child development and background knowledge on the demographic characteristics of the participants. Special focuses of the training were interview and communication techniques including de-escalation methods. Interviewers were sensitized for signs of suicidality and child abuse and instructed how to handle these. They were prepared for problematic situations such as disruptive behavior of the child. The interviewers were certified for the correct application of the measures and tests. Certification was, whenever necessary, provided by external institutions (i.e., for the Kinder-DIPS). All project staff members, including research assistants and interns, were sworn to confidentiality (according to $\$ 5$ BDSG) upon start of their employment. Should signs for child abuse be uncovered during the study, a conflict between psychological /scientific confidentiality and the 




Fig. 1 Schedule of Pro Kind Follow-up 
obligation to protect the child's wellbeing might arise. In such a situation, the specific case and the suspicions of the interviewer will be first discussed with the project leader and the necessity to involve third parties evaluated. Before legal action is pursued it will be examined whether personal communication and sensitizing parents regarding the issue at hand as well as encouraging help-seeking behavior in the affected families are sufficient and justifiable ( $\$ 4$ Absatz $1 \mathrm{KKG}$ ). It is, furthermore, possible to request anonymous legal advice from local authorities $(\$ 4$ Absatz 2 $K K G)$. Based on German law, personal information will only be relayed to third parties when the child's wellbeing is clearly at stake and any attempts of arranging for help remained unsuccessful ( $\$ 4$ Absatz 3 KKG). All members of staff are extensively trained regarding legal matters as well as personal behavior in such situations.

\section{Assessment of contact details}

Participants are first contacted by the KFN via mail. In this letter participants are informed about the study and can send back a postcard with a current telephone number. In case this initial mail cannot be delivered, the local registration office (Einwohnermeldeamt) is contacted and asked for the current contact details (name and address) of participants. A project assistant then establishes first personal contact via telephone. During this initial phone call appointments for the home visits as well as for the telephone interviews are scheduled.

\section{Computer-aided telephone interviews (CATI)}

As during the first program phase, scales from the German Socio-Economic Panel (SOEP) [49] as well as the study regarding the health of children and youths in Germany (KiGGS [50]) are used to gather socio-demographic data as well as data regarding the use of health services. In addition, psychometric scales are presented to assess relevant areas that include the mothers' current living conditions (e.g., the mothers' general health and social support), as well as that of the children (e.g., general development and socio-emotional development). Furthermore, parts of a fully standardized diagnostic interview, corresponding to the Expert System for Diagnosis of Mental Disorders (Diagnostisches Expertensystem für Psychische Störungen, DIA-X; [51]), are conducted to identify possible mental disorders and problems on the part of the mothers. A trained project team member conducts two telephone interviews with each participant.

\section{On-site interviews}

In a 2.5 -h home visit, two professionally trained project team members conduct structured interviews with the mother and developmental tests with the reference child. These outcome assessors are unaware whether the families are part of the intervention or control group. After an introductory and instruction phase on the part of a project team member, the mother's consent for testing the children is obtained. All relevant materials are presented to her and she is, furthermore, informed in detail about the test procedures. Subsequently, the Diagnostic Interview for Mental Disorders for Children and Adolescents (Kinder-DIPS; [52]) is conducted, whereupon the mother is given a paper-pencil questionnaire to complete. In case an interview or psychological testing is too exhausting for mother or child it is possible to schedule additional appointments to continue the interview and/or testing.

At the same time - with the mother's consent - the second project team member carries out a structured interview with the child. The children are thereby interviewed regarding their experiences of neglect, based on picture card-based, age-appropriate, structured interviews (Multidimensional Neglectful Behavior Scale, MNBS [53]) and regarding minor physical abuse (Conflict Tactic Scale, CTS-CV [54]). In order to prevent severe stress for the children, only a few, low-intrusive scales are used. No questions are asked concerning experiences of severe violence. The children, furthermore, complete the test battery BUEGA (Basisdiagnostik Umschriebener Entwicklungsstörungen im Grundschulalter (Basic diagnostics of specific developmental disorders in elementary school children [55]) and three structured game situations regarding (1) risk behavior according to Dohmen and colleagues [56], (2) pro-social behavior according to Fehr and colleagues [57] and (3) time preference according to Mischel and colleagues [58]. The testing and games that are carried out with the children are entirely age appropriate and playful. Nevertheless, the mere length of the session requires a significant amount of focus and motivation on behalf of the child. It is, hence, possible to divide the tests between at least two sessions should the child show signs of exhaustion or lack of motivation. The test administrator will, together with the mother, make sure that the child's needs are met and a good relationship of child and test administrator can be established to ensure optimal testing conditions. The children's participation is entirely voluntary. Children are informed that there will be no negative consequences should they decide not to participate. Furthermore, children are assured that the answers that they provide are confidential. Children are also informed of their right to quit the interview or testing at any moment.

\section{Expert judgment}

After the on-site interviews, both project team members individually gather observations on site in the domestic environment regarding the living situation, the wellbeing of the child, as well as the quality of the parent-child relationship. Observations are rated according to the 
scales of the Home Observation for Measurement of the Environment (HOME [59]).

\section{Compensation of participants}

All participants receive $€ 80$ as compensation for the time invested in the telephone interview, face-to face interview and developmental testing. In case only one interview can be conducted the participant receives $€ 30$ (telephone interview) or $€ 50$ (home visit), respectively. Every child receives a little gift after the home visit (worth approx. €10).

\section{Communication of disconcerting test results}

The results of the developmental tests (intelligence test, vocabulary test) and diagnostic interviews (DIA-X, Kinder-DIPS) are shared with the parents and explained using an appropriate, yet easily understandable, language. The project staff is available should participants have further questions regarding test results. Upon request project staff members will also assist in the arrangement of counseling or support services for mother or child.

\section{Administrative data}

In addition to the survey methods mentioned above, administrative data from various sources are used. According to the first project phase, data regarding inpatient and outpatient treatment, as well as medication, aids, mother-child therapies and speech therapy are made available by AOK Niedersachsen, Bremen and Sachsen (German public health insurance company). Here, among other information, it is documented whether vaccinations, early screenings, etc. have been attended at health facilities. Furthermore, information is gathered regarding previous employment, phases of unemployment, and participation in measures during unemployment as well as employment details from the Technical Data Center (FDZ) of the Institute for Employment Research (IAB) of the Federal Employment Agency in Nuremberg. It was possible for the participants to provide self-report data but not grant the researchers access to administrative data.

\section{Data handling and monitoring}

Data collection and management is overseen by the KFN data manager. He is employed directly by the KFN and not involved in the project either monetarily or scientifically. All project team members have received extensive professional training regarding the application of the measures, data confidentiality but also regarding possible signs of suicidality, child abuse or neglect. All telephone interviews are recorded and evaluated by a second research assistant regarding proper conduct as well as signs of suicidality, child abuse or neglect. Audio- and video-recordings are saved with the primary sponsor and only shared with secondary sponsors for data analysis as stated in the consent form (see Additional file 2). Neither audio nor video transcripts contain personal information beyond the child's first name and the mother's initials. After data analysis, video material has to be blurred for alienation purposes or deleted. All outcome assessors were blinded regarding intervention vs. control group membership of the families. Questionnaires were transported in a sealed envelope without identifying personal information beyond a code for longitudinal matching. Personal information was only used for contacting the participants. The personal information is not stored together with the outcome data and is only accessible on a need to know basis.

\section{Evaluation of effectiveness}

The main focus of the scientific work objective is to answer the following research questions (please see Fig. 2 for the intervention's internal logic. The model shows its hypothesized, causal mechanisms based on a model presented by Olds [10]):

Research question 1: Does the home-visiting program Pro Kind exert a positive effect on the cognitive and socio-emotional development, as well as on the physical health of the child in the medium term?

- Hypothesis 1.1: The home-visiting program has a positive effect on the child's cognitive development and school performance.

- Hypothesis 1.2: The home visits have a positive effect on the child's mental health.

- Hypothesis 1.3: The home visits have a positive effect on the child's socio-emotional development.

- Hypothesis 1.4: The home visits have a positive effect on the child's life satisfaction.

- Hypothesis 1.5: The home visits influence the child's preferences (risk behavior, pro-sociality and time preference).

Research question 2: Does the home-visiting program Pro Kind, in the medium term, influence the frequency and intensity of parental violence and child neglect?

- Hypothesis 2.1: The home visits result in improved parenting skills (less inappropriate parenting behavior).

- Hypothesis 2.2: The home visits reduce or prevent child abuse as well as the frequency of physical violence.

- Hypothesis 2.3: The home visits reduce or prevent child neglect.

Research question 3: Does the home-visiting program Pro Kind have a positive effect on the psychosocial situation as well as on the mothers' mental health? 


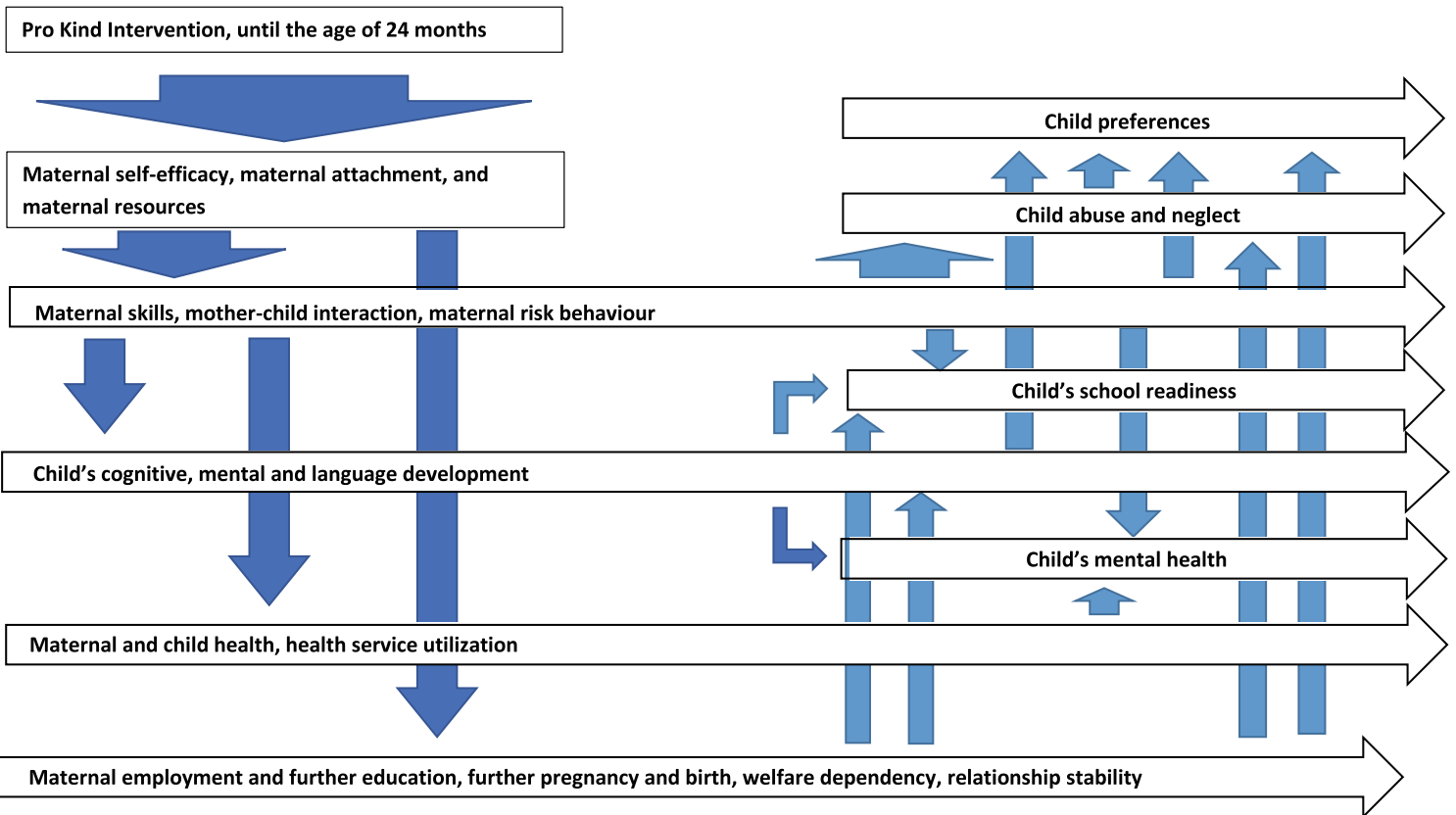

Fig. 2 Intervention's logic model following Olds [10]

- Hypothesis 3.1: The home visits have a positive effect on the mother's perceived social support.

- Hypothesis 3.2: The home visits influence the mother's mental health.

- Hypothesis 3.3: The home visits result in more stable partnerships with less frequent partner change, greater satisfaction with the partnership and less domestic violence in the partnership.

- Hypothesis 3.4: The home visits improve the parental self-efficacy expectations concerning the parenting tasks.

- Hypothesis 3.5: The home visits have a positive effect on the perceived stress resulting from the mother's parenting tasks.

- Hypothesis 3.6: The home visits have a positive effect on the mother's life satisfaction.

Research question 4: Does the home-visiting program Pro Kind positively influence the socio-economic situation in the family?

- Hypothesis 4.1: The home visits increase the share of mothers in employment or education programs.

- Hypothesis 4.2: The home visits reduce the families' use of welfare payments (SGB II, SGB III and SGB VIII (social security codes)).
- Hypothesis 4.3: The home visits have a positive effect on the family's living situation.

- Hypothesis 4.4: The home visits influence the timing or frequency of a renewed pregnancy and births.

Research question 5: Does the home-visiting program Pro Kind have a positive effect on the family's physical health and health service utilization?

- Hypothesis 5.1: The home visits improve the mothers' physical health.

- Hypothesis 5.2: The home visits increase the frequency of pediatric primary care use (e.g., screenings, vaccinations, child's oral health care and dentist visits).

- Hypothesis 5.3: Home visits reduce the children's hospital visits (outpatient or inpatient) caused by accidents and injuries.

Table 1 briefly describes the procedures used to evaluate the program. It is of special importance whether the underlying constructs are (1) based on a direct efficiency hypothesis of the Pro Kind program (primary outcome) or (2) based on an efficiency hypothesis, but one that must be regarded as less probable than a primary outcome (i.e., secondary outcome) for the following two reasons. First, the intervention did not directly focus on the secondary 
Table 1 List of procedures of biopsychosocial evaluation of the Pro Kind Follow-up

\begin{tabular}{|c|c|c|c|c|c|}
\hline Hypothesis & Construct & Operationalization & $\begin{array}{l}\text { Primary or secondary } \\
\text { outcome domains }\end{array}$ & Informant & Data source \\
\hline \multirow{3}{*}{$\begin{array}{l}\text { Hypothesis 1.1: The home-visiting } \\
\text { program has a positive effect on } \\
\text { the child's cognitive development } \\
\text { and school performance }\end{array}$} & $\begin{array}{l}\text { Child's school } \\
\text { performance }\end{array}$ & \multirow{3}{*}{$\begin{array}{l}\text { Basic diagnostics of specific } \\
\text { developmental disorders of } \\
\text { speech and language at } \\
\text { primary school age (BUEGA } \\
\text { [55]) }\end{array}$} & \multirow{3}{*}{$\begin{array}{l}\text { Primary } \\
\text { outcome } \\
\text { domain }\end{array}$} & \multirow[t]{3}{*}{ Child } & \multirow{3}{*}{$\begin{array}{l}\text { Testing by } \\
\text { trained test } \\
\text { administrator }\end{array}$} \\
\hline & $\begin{array}{l}\text { Child's cognitive } \\
\text { development }\end{array}$ & & & & \\
\hline & $\begin{array}{l}\text { Child's specific } \\
\text { developmental } \\
\text { disorders }\end{array}$ & & & & \\
\hline \multirow[t]{4}{*}{$\begin{array}{l}\text { Hypothesis 1.2: The home visits } \\
\text { have a positive effect on the } \\
\text { child's mental health }\end{array}$} & $\begin{array}{l}\text { Child's behavioral } \\
\text { problems and } \\
\text { emotional disorders }\end{array}$ & $\begin{array}{l}\text { Child Behavior Checklist } \\
\text { (CBCL 6/18 R [60]), German } \\
\text { version: [61] }\end{array}$ & \multirow[t]{4}{*}{$\begin{array}{l}\text { Primary } \\
\text { outcome } \\
\text { domain }\end{array}$} & Mother & Questionnaire \\
\hline & $\begin{array}{l}\text { Child's attention deficit } \\
\text { hyperactivity disorder } \\
\text { and social behavior } \\
\text { disorders (suspected } \\
\text { diagnosis) }\end{array}$ & \multirow[t]{3}{*}{$\begin{array}{l}\text { Module from the diagnostic } \\
\text { interview of mental disorders } \\
\text { in children and youths } \\
\text { (Kinder-DIPS [52]) }\end{array}$} & & \multirow[t]{3}{*}{ Mother } & \multirow[t]{3}{*}{$\begin{array}{l}\text { Interview by } \\
\text { trained and } \\
\text { certified staff }\end{array}$} \\
\hline & $\begin{array}{l}\text { Child's anxiety disorders } \\
\text { (suspected diagnosis) }\end{array}$ & & & & \\
\hline & $\begin{array}{l}\text { Child's affective disorders } \\
\text { (suspected diagnosis) }\end{array}$ & & & & \\
\hline \multirow{3}{*}{$\begin{array}{l}\text { Hypothesis 1.3: The home visits } \\
\text { have a positive effect on the } \\
\text { child's socio-emotional } \\
\text { development }\end{array}$} & Child's social skills & $\begin{array}{l}\text { Social Skills Improvement } \\
\text { System (SSIS [62]), German } \\
\text { version: author's translation }\end{array}$ & \multirow[t]{3}{*}{$\begin{array}{l}\text { Secondary } \\
\text { outcome } \\
\text { domain }\end{array}$} & Mother & Questionnaire \\
\hline & Child's aggression & $\begin{array}{l}\text { Questionnaire regarding } \\
\text { children's aggressive } \\
\text { behavior (FAVK [63]) }\end{array}$ & & Mother & Questionnaire \\
\hline & Child's psychopathy & $\begin{array}{l}\text { Inventory of Callous-Unemotional } \\
\text { Traits (ICU) ([64]), German version } \\
\text { by Essau }\end{array}$ & & Mother & Questionnaire \\
\hline $\begin{array}{l}\text { Hypothesis 1.4: The home visits } \\
\text { have a positive effect on the } \\
\text { child's life satisfaction. }\end{array}$ & Child's general life satisfaction & $\begin{array}{l}\text { Inventory to measure the life } \\
\text { quality of children and youths } \\
\text { (ILK [65]) }\end{array}$ & $\begin{array}{l}\text { Primary } \\
\text { outcome } \\
\text { domain }\end{array}$ & Child & $\begin{array}{l}\text { Survey by } \\
\text { trained test } \\
\text { administrator }\end{array}$ \\
\hline \multirow{2}{*}{$\begin{array}{l}\text { Hypothesis } 1.5 \text { : The home visits } \\
\text { influence the child's preferences } \\
\text { (risk behavior, pro-social behavior } \\
\text { and time preference) }\end{array}$} & $\begin{array}{l}\text { Child's pro-social } \\
\text { behavior }\end{array}$ & $\begin{array}{l}\text { Game for interpersonal allocation } \\
\text { decisions ([57]). }\end{array}$ & \multirow{2}{*}{$\begin{array}{l}\text { Secondary } \\
\text { outcome } \\
\text { domain }\end{array}$} & \multirow[t]{2}{*}{ Child } & \multirow{2}{*}{$\begin{array}{l}\text { Testing by } \\
\text { trained test } \\
\text { administrator }\end{array}$} \\
\hline & Child's risk behavior & Investment decisions in a & & & \\
\hline
\end{tabular}
and time preference).

Hypothesis 2.1: The home visits result in improved parenting skills (less inappropriate parenting behavior)

Hypothesis 2.2: The home visits reduce or prevent child abuse and the frequency of physical violence
Child's time preference

Mother's dysfunctional parenting

Mother's non-violent disciplining

Mother's child abuse

Mother's "Minor" aggression

Mother's "Minor" physical violence lottery ([56])

Game for temporary allocation decisions ([58])

Parenting Scale (PS) ([66]), German version: target-group-specific adaptation by the authors

Primary

outcome

Mother

Questionnaire

Conflict Tactic Scale Child Report

(CTS-CR [68]), interview of the children with picture cards. German version: translation by the AMIS

group / Conflict Tactic Scale Parent Child (CTS-PC [67]), German version: target-group-specific adaptation by the authors

Conflict Tactic Scale Parent Child (CTS-PC) ([54]), German version: target-group-specific adaptation by the authors

Conflict Tactic Scale Child Report

(CTS-CR [68]), interview of the

children with picture cards.

German version: translation

by the AMIS group / Conflict

Tactic Scale Parent Child

(CTS-PC) ([54]), German version:

target-group-specific adaptation

by the authors

\begin{tabular}{|c|c|c|}
\hline & $\begin{array}{l}\text { Child / } \\
\text { Mother }\end{array}$ & $\begin{array}{l}\text { Interview } \\
\text { through } \\
\text { trained test } \\
\text { administrator } \\
\text { (Child) / } \\
\text { Questionnaire } \\
\text { (Mother)] }\end{array}$ \\
\hline \multirow[t]{2}{*}{$\begin{array}{l}\text { Primary } \\
\text { outcome } \\
\text { domain }\end{array}$} & Mother & Questionnaire \\
\hline & $\begin{array}{l}\text { Child / } \\
\text { mother }\end{array}$ & $\begin{array}{l}\text { Interview } \\
\text { through } \\
\text { trained test } \\
\text { administrator } \\
\text { (Child) / } \\
\text { Questionnaire } \\
\text { (Mother) }\end{array}$ \\
\hline
\end{tabular}


Table 1 List of procedures of biopsychosocial evaluation of the Pro Kind Follow-up (Continued)

\begin{tabular}{|c|c|c|c|c|c|}
\hline Hypothesis & Construct & Operationalization & $\begin{array}{l}\text { Primary or secondary } \\
\text { outcome domains }\end{array}$ & Informant & Data source \\
\hline \multirow{4}{*}{$\begin{array}{l}\text { Hypothesis 2.3: The } \\
\text { home visits } \\
\text { reduce or prevent } \\
\text { child neglect }\end{array}$} & $\begin{array}{l}\text { Mother's physical } \\
\text { neglect }\end{array}$ & \multirow{4}{*}{$\begin{array}{l}\text { Scale of the Multidimensional } \\
\text { Neglectful Behavior Scale-Child } \\
\text { Report (MNBS [53]), interview } \\
\text { of the children with picture } \\
\text { cards. German version: } \\
\text { translation by the AMIS group. }\end{array}$} & \multirow{4}{*}{$\begin{array}{l}\text { Primary } \\
\text { outcome } \\
\text { domain }\end{array}$} & & \\
\hline & $\begin{array}{l}\text { Mother's emotional } \\
\text { neglect }\end{array}$ & & & \multirow[t]{3}{*}{ Child / mother } & \multirow{3}{*}{$\begin{array}{l}\text { Interview } \\
\text { through } \\
\text { trained test } \\
\text { administrator } \\
\text { (Child) / } \\
\text { Questionnaire } \\
\text { (Mother) }\end{array}$} \\
\hline & $\begin{array}{l}\text { Mother's cognitive } \\
\text { neglect }\end{array}$ & & & & \\
\hline & $\begin{array}{l}\text { Mother's supervisory } \\
\text { neglect }\end{array}$ & & & & \\
\hline $\begin{array}{l}\text { Hypothesis 3.1: The home visits } \\
\text { have a positive effect on the } \\
\text { mother's perceived social } \\
\text { support }\end{array}$ & $\begin{array}{l}\text { Mother's Perceived } \\
\text { social support }\end{array}$ & $\begin{array}{l}\text { Questionnaire regarding social } \\
\text { support (FSOZU-K6 [71]) }\end{array}$ & $\begin{array}{l}\text { Secondary } \\
\text { outcome } \\
\text { domain }\end{array}$ & Mother & Questionnaire \\
\hline $\begin{array}{l}\text { Hypothesis 3.2: The home visits } \\
\text { influence the mother's mental } \\
\text { health }\end{array}$ & Mother's mental stress & $\begin{array}{l}\text { Depression-Anxiety-Stress Scale } \\
\text { (DASS [70]), German version: } \\
\text { target-group-specific adaptation } \\
\text { by the authors }\end{array}$ & $\begin{array}{l}\text { Primary } \\
\text { outcome } \\
\text { domain }\end{array}$ & Mother & Questionnaire \\
\hline \multirow{6}{*}{$\begin{array}{l}\text { Hypothesis 3.3: The home visits } \\
\text { result in more stable partnerships } \\
\text { with less frequent partner change, } \\
\text { greater satisfaction with the } \\
\text { partnership and less domestic } \\
\text { violence in the partnership }\end{array}$} & $\begin{array}{l}\text { Mother's stability of } \\
\text { partnership }\end{array}$ & Developed by the authors & \multirow{6}{*}{$\begin{array}{l}\text { Secondary } \\
\text { outcome } \\
\text { domain }\end{array}$} & \multirow[t]{6}{*}{ Mother } & \multirow[t]{6}{*}{ Questionnaire } \\
\hline & $\begin{array}{l}\text { Mother's partnership } \\
\text { satisfaction }\end{array}$ & $\begin{array}{l}\text { Short form of the Partnership } \\
\text { Questionnaire (PFB-K [74]) }\end{array}$ & & & \\
\hline & $\begin{array}{l}\text { Psychological aggression } \\
\text { against mother }\end{array}$ & \multirow{4}{*}{$\begin{array}{l}\text { Conflict Tactics Scales (CTS2 [54]; } \\
\text { German version: target-group- } \\
\text { specific adaptation by the authors } \\
\text { [forward-backward] }\end{array}$} & & & \\
\hline & $\begin{array}{l}\text { Physical violence against } \\
\text { mother }\end{array}$ & & & & \\
\hline & $\begin{array}{l}\text { Sexual assault against } \\
\text { mother }\end{array}$ & & & & \\
\hline & $\begin{array}{l}\text { Injuries due to assaults } \\
\text { by the partner }\end{array}$ & & & & \\
\hline $\begin{array}{l}\text { Hypothesis 3.4: The home visits } \\
\text { improve the parental self-efficacy } \\
\text { expectations regarding the } \\
\text { parenting tasks }\end{array}$ & $\begin{array}{l}\text { Mother's parenting } \\
\text { self-efficacy }\end{array}$ & $\begin{array}{l}\text { Parenting Sense of Competence } \\
\text { Scale (PSOC) ([76]), German } \\
\text { version: target-group-specific } \\
\text { adaptation by the authors }\end{array}$ & $\begin{array}{l}\text { Secondary } \\
\text { outcome } \\
\text { domain }\end{array}$ & Mother & Questionnaire \\
\hline $\begin{array}{l}\text { Hypothesis 3.5: The home visits } \\
\text { have a positive effect on the } \\
\text { perceived stress resulting from } \\
\text { the mother's parenting tasks }\end{array}$ & Mother's parenting stress & $\begin{array}{l}\text { Parenting Stress Index (PSI [72]), } \\
\text { German version: Eltern-Belastungs- } \\
\text { Inventar (EBI [73]). }\end{array}$ & $\begin{array}{l}\text { Secondary } \\
\text { outcome } \\
\text { domain }\end{array}$ & Mother & Questionnaire \\
\hline $\begin{array}{l}\text { Hypothesis 3.6:The home visits } \\
\text { have a positive effect on the } \\
\text { mother's life satisfaction }\end{array}$ & $\begin{array}{l}\text { Mother's general life } \\
\text { satisfaction }\end{array}$ & $\begin{array}{l}\text { Questions regarding life } \\
\text { satisfaction (FLZ [77]) }\end{array}$ & $\begin{array}{l}\text { Primary } \\
\text { outcome } \\
\text { domain }\end{array}$ & Mother & Questionnaire \\
\hline \multirow{2}{*}{$\begin{array}{l}\text { Hypothesis } 4.1 \text { : The home visits } \\
\text { increase the share of mothers } \\
\text { in employment or education } \\
\text { programs }\end{array}$} & $\begin{array}{l}\text { Mother's acceptance } \\
\text { of employment }\end{array}$ & $\begin{array}{l}\text { The German Socio-Economic } \\
\text { Panel (SOEP) [49] and }\end{array}$ & \multirow{2}{*}{$\begin{array}{l}\text { Secondary } \\
\text { outcome } \\
\text { domain }\end{array}$} & Mother & Questionnaire \\
\hline & $\begin{array}{l}\text { Mother's acceptance } \\
\text { of training or } \\
\text { educational offers }\end{array}$ & $\begin{array}{l}\text { The Panel Arbeitsmarkt } \\
\text { und Soziale Sicherung ([78]) }\end{array}$ & & Mother & Questionnaire \\
\hline $\begin{array}{l}\text { Hypothesis 4.2: The home } \\
\text { visits reduce the families' } \\
\text { use of welfare payments } \\
\text { (SGB II, SGB III and SGB VIII } \\
\text { [social security codes]). }\end{array}$ & Welfare payments & $\begin{array}{l}\text { Integrated employment history } \\
\text { provided by the Institute of } \\
\text { Employment Research (IAB) }\end{array}$ & $\begin{array}{l}\text { Secondary } \\
\text { outcome } \\
\text { domain }\end{array}$ & $\begin{array}{l}\text { Institute of } \\
\text { Employment } \\
\text { Research } \\
\text { (IAB) }\end{array}$ & $\begin{array}{l}\text { Administrative } \\
\text { data }\end{array}$ \\
\hline $\begin{array}{l}\text { Hypothesis 4.3: The home } \\
\text { visits have a positive effect } \\
\text { on the family's living situation }\end{array}$ & Family situation & $\begin{array}{l}\text { The Home Observation for } \\
\text { Measurement of the } \\
\text { Environment (HOME [59] } \\
\text { forward-backward } \\
\text { translation by the authors) }\end{array}$ & $\begin{array}{l}\text { Secondary } \\
\text { outcome } \\
\text { domain }\end{array}$ & Staff & Observation \\
\hline \multirow{4}{*}{$\begin{array}{l}\text { Hypothesis 4.4: The home } \\
\text { visits influence the timing } \\
\text { or frequency of a renewed } \\
\text { pregnancy and births }\end{array}$} & Renewed pregnancy & \multirow{3}{*}{$\begin{array}{l}\text { Questionnaire about intended } \\
\text { and realized fertility (Siedler } \\
\text { et al., 2009). } \\
\text { Integrated Employment History } \\
\text { provided by the Institute of } \\
\text { Employment Research (IAB) }\end{array}$} & \multirow{4}{*}{$\begin{array}{l}\text { Secondary } \\
\text { outcome } \\
\text { domain }\end{array}$} & \multirow{3}{*}{$\begin{array}{l}\text { Mother/ } \\
\text { Institute of } \\
\text { Employment } \\
\text { Research } \\
\text { (IAB) }\end{array}$} & \multirow{3}{*}{$\begin{array}{l}\text { Questionnaire/ } \\
\text { administrative } \\
\text { data }\end{array}$} \\
\hline & $\begin{array}{l}\text { Renewed desire to } \\
\text { have children }\end{array}$ & & & & \\
\hline & Abortions Births & & & & \\
\hline & Mother's physical health & & & Mother & Questionnaire \\
\hline
\end{tabular}


Table 1 List of procedures of biopsychosocial evaluation of the Pro Kind Follow-up (Continued)

\begin{tabular}{|c|c|c|c|c|c|}
\hline Hypothesis & Construct & Operationalization & $\begin{array}{l}\text { Primary or secondary } \\
\text { outcome domains }\end{array}$ & Informant & Data source \\
\hline $\begin{array}{l}\text { Hypothesis 5.1: The home } \\
\text { visits improve the mothers' } \\
\text { physical health }\end{array}$ & & $\begin{array}{l}\text { 12-Item Short Form Survey } \\
\text { (SF-12 [79]) }\end{array}$ & $\begin{array}{l}\text { Secondary } \\
\text { outcome } \\
\text { domain }\end{array}$ & & \\
\hline $\begin{array}{l}\text { Hypothesis 5.2: The home } \\
\text { visits increase the frequency } \\
\text { of pediatric primary care use } \\
\text { (e.g., screenings, vaccinations, } \\
\text { child's oral health care and } \\
\text { dentist visits) }\end{array}$ & $\begin{array}{l}\text { Frequency of pediatric } \\
\text { primary care use }\end{array}$ & $\begin{array}{l}\text { KiGGS questionnaire [80] } \\
\text { physician visits with ICD Z }\end{array}$ & $\begin{array}{l}\text { Secondary } \\
\text { outcome } \\
\text { domain }\end{array}$ & $\begin{array}{l}\text { Mother } \\
\text { health } \\
\text { insurance } \\
\text { companies }\end{array}$ & $\begin{array}{l}\text { Questionnaire/ } \\
\text { administrative } \\
\text { data }\end{array}$ \\
\hline $\begin{array}{l}\text { Hypothesis 5.3: Home visits } \\
\text { reduce the children's hospital } \\
\text { visits (outpatient or inpatient) } \\
\text { caused by accidents and injuries }\end{array}$ & $\begin{array}{l}\text { Number of child's } \\
\text { injuries }\end{array}$ & $\begin{array}{l}\text { Hospital admission and } \\
\text { physician visits with ICD S } \\
\text { and T }\end{array}$ & $\begin{array}{l}\text { Secondary outcome } \\
\text { domain }\end{array}$ & $\begin{array}{l}\text { Health } \\
\text { insurance } \\
\text { companies }\end{array}$ & $\begin{array}{l}\text { Administrative } \\
\text { data }\end{array}$ \\
\hline
\end{tabular}

outcomes, (e.g., child preferences); second, we have less power for the outcomes, (e.g., administrative health services utilization data is only available for one third of the sample as we only cooperate with the largest health insurance company in Germany). Lastly, (3) a construct will be assessed for future research questions but is not regarded as an original aim of the intervention (i.e., no outcome). Due to the amount of data that is to be gathered, in the following only the primary and secondary outcome domains will be presented. The documentation of the study can furthermore be viewed at the German Register of Clinical Trials (DRKS; ID: DRKS000007554. Registration date 11 June 2015; updated on 24 August 2017). In the following, the procedures presented in Table 1 will be described in more detail.

\section{Deployed measuring instruments \\ Research question 1: The child's development}

School performance and specific learning disability The Basic Diagnostics of Specific Developmental Disorders in Elementary School Age Children (BUEGA; [55]) is an elementary school test battery that aims to measure relevant specific developmental and attention disorders in elementary school children (6-10 years old). It is also possible to use the procedure to evaluate the school achievement potential. Furthermore, an aptitude profile can be created that illustrates the child's strengths and weaknesses. The BUEGA consists of seven subtests: Verbal intelligence (52 items), Non-verbal intelligence (38 items), Expressive language (57 items), Reading (32 items), Spelling (10 to 18 items, depending on the grade level), Arithmetic (40 items) and Attentiveness (strike-through test). The reliabilities for the different scales are between Cronbach's $\alpha=.79$ and .96 .

Mental health The Child Behavior Checklist (CBCL 6/18 [60]) measures behavioral problems, emotional problems, somatic complaints, as well as social competences of school-age children and youths from their parent's perspective. The eight syndrome scales (withdrawn/depressed, somatic complaints, anxious/depressed, social problems, thought problems, attention problems, rule-breaking behavior and aggressive behavior) can be summed up to scales of internalizing and externalizing disorders as well as to an overall sum score. Appropriate internal consistencies of Cronbach's $\alpha>.80$ are reported in the German manual [61] for the total problem score and the scales internalizing behavior and externalizing behavior.

When dealing with mental disorders in children and adolescents, the Diagnostic Interview for Children and Youths (Kinder-DIPS; [52]) allows for a diagnosis of mental disorders according to DSM-IV and ICD-10. It encompasses both a parental and a children's version (for children from the age of 6 years). It allows the assessment of a wide spectrum of current and lifetime mental disorders in children and adolescents: attention problems, activity problems and social problems, tic disorders, anxiety disorders, elimination disorders, sleep disorders, affective disorders and eating disorders. Furthermore, it contains a general clinical-demographic part as well as several screenings (e.g., for alcoholism, drug abuse, as well as non-organic psychosis). In addition, a psychiatric history, a family history of mental disorders as well as Axes IV (Psychosocial and environmental problems) and V (Global measurement of the level of functioning) can be assessed. To measure the occurrence of symptoms, the frequency of occurrence or the intensity of a symptom is coded on a 4-point rating scale (never/seldom to very often, or never to very strong). For the individual disorder categories, the interrater reliabilities of the parental version (long-term diagnoses) lie between Kappa $=.48$ (sleep disorders) and Kappa $=.88$ (affective disorders). The following modules of the parental version are to be covered within the present study: attention-deficit hyperactivity disorder, anxiety disorders and affective disorders. 


\section{Socio-emotional development}

Social competence The Social Skills Improvement System (SSIS [62]; in a translation by the authors adapted to the target group (forward-backward) makes it possible to measure the social skills of children and youths between the ages of 3 and 18 years. The SSIS instrument consists of several scales to measure three domains: Social Skills (subscales: Communication, Cooperation, Assertion, Empathy, Engagement and Self-Control), Problem Behaviors (subscales: Externalizing, Internalizing, Hyperactivity/Inattentiveness, Autism Spectrum and Bullying) and Academic Competence (subscales: Reading, Mathematics, Motivation, Support by parents and General Cognitive Function). In the present study, the domain Social Skills will be included as part of the maternal assessment.

Aggressiveness The German questionnaire for aggressive behavior in children (FAVK, "Fragebogen zum aggressiven Verhalten von Kindern" [63]) assesses triggering and maintaining components of aggressive behavior. The external assessment version for parents, teachers and educators will be filled out from the mother. A distinction is made between aggressive behaviors and cognitions toward peers and adults. The FAVK consists of 25 items with a 4-point rating scale on how applicable the behavior is (ranging from not applicable at all to particularly applicable). Four facets of aggressive behavior are measured: social-cognitive information processing disorders, impulse control disorders, social skills disorders and social interaction disorders. The internal consistency of the questionnaire ranges between Cronbach's $\alpha=.92$ and .95 .

Psychopathy The Inventory of Callous-Unemotional Traits (ICU) [64] measures callous, cunning and hard-hearted qualities and is based on the Callous Unemotional scale of the APSD. The ICU consists of three scales: Callousness, Uncaring and Unemotional and contains a total of 24 items. The teachers are to assess the occurrence of behaviors by children on a four-stage scale (not at all true to definitely true). The documented internal consistency of the ICU is between Cronbach's $\alpha=.64$ and .77 .

Life satisfaction To measure the life quality of children and youths a German inventory is administered ("Inventar zur Erfassung der Lebensqualität bei Kindern und Jugendlichen", ILK [65]). Life quality is divided into different areas that are measured separately: school, family, social contact with peers and interests and recreational activities. Furthermore, there are two health-related topics: physical health and mental health. In addition to the individual areas, an overall assessment of quality of life is possible. The entire self-assessment version of the
ILK (apart from the health-oriented areas) is to be used when interviewing the child. Seven items are thus presented with an answer format suitable for children (Smiley symbols). The internal consistency of the life quality scores for children and youths range between Cronbach's $\alpha=.55$ and .63 .

\section{Children's preferences}

Pro-social behavior The game regarding interpersonal allocation decisions [57] consists of four rounds. In each round, the child can choose between an egalitarian allocation and an alternative where the child gains an advantage or disadvantage over other imaginary children. In the pro-social decision situation, the child can choose between the allocation (1-1), which means 1 point for the child and 1 point for the imaginary other children, and the allocation $(1-0)$. This allocation allows the child to distribute a point to the other imaginary children without additional costs. In the cost-incurring pro-social decision situation, the child is to choose between a (1-1) and (2-0) allocation. The child can only increase their own payment at the expense of the imaginary children. In the envy decision situation, the child chooses between the allocation (1-1) and (1-2), which makes it possible for the child to reduce the payment to the imaginary children without incurring any costs of their own. In the cost-incurring envy decision situation the child chooses between the allocation (1-1) and (2-4), which leads to a reduction of the payment to the imaginary children that incurs costs of their own.

Risk behavior The game Investment decision in a lottery [56] measures the child's willingness to take risks. Before each round the child can bet between zero and five points in a lottery, in which they can double their points with a probability of $50 \%$ or lose the points they have bet with a probability of $50 \%$. Points that are not bet are safe for the child. The number of points that are bet can be regarded as a measure of the child's willingness to take on risk.

Time preference The game regarding temporary allocation decisions [58] makes it possible to assess the child's individual time preference. In this game, the child can choose whether they want to immediately receive the points won in the previous game, exchange them for a present or continue to collect further points by deciding to receive the present at a later point in time. The child receives 2 points for every week that they waits. The child can wait for a maximum of 4 weeks. The number of weeks can be regarded as a measure of the individual time preference. 
Research question 2: Dysfunctional parenting behavior, child abuse and child neglect Dysfunctional parenting behavior

The Parenting Scale (PS [66] in a translation by the authors adapted to the target group (forward-backward)) measures dysfunctional disciplinary parenting behavior. Based on examples of children's behavior, the parents are to classify their own behavior ranging between functional and dysfunctional.

\section{Child abuse}

The Parent-Child Conflict Tactic Scales (CTS-PC [67] in a translation by the authors adapted to the target group (forward-backward)), is a parent-child version of the CTS that measures psychological and physical abuse and neglect, as well as non-violent disciplining of children by their parents. The instrument contains 35 items and can be used when interviewing the mother, whereby she rates her own behavior toward her child. The CTS-PC is composed of the subscales nonviolent discipline, psychological aggression, physical assault, neglect, weekly discipline and sexual abuse.

The CTS-PC, Child Report assesses conflict resolution strategies in family or close relationships as rated by the children. In line with the parent-version, the child version measures psychological and physical abuse and neglect, as well as nonviolent disciplining of children by their parents. It is designed for 6- to 9-year-olds. It operates with pictures that describe conflict situations in the family that the child may possibly recognize. The pictures depict different levels of severity, whereby only the three dimensions non-violent discipline, psychological aggression and minor physical assault are used in the present study. A psychometric evaluation of the adapted German version of the CTS-PC was recently conducted by the AMIS (analyzing pathways from childhood maltreatment to internalizing symptoms and disorders in children and adolescents) study of the University of Leipzig [68].

\section{Child neglect}

The Multidimensional Neglectful Behavior Scale (MNBS [69]; German version translated for the AMIS study of the University of Leipzig) assesses various forms of parental behavior regarding child neglect. There are various versions of the MNBS, and all of them measure the extent to which the following needs of a child have been neglected: Physical needs (e.g., food and clothing), emotional needs (e.g., affection and support), supervisory needs (e.g., taking an interest in the child's misconduct and knowledge about their whereabouts) and cognitive needs (e.g., reading out loud or helping with homework). The MNBS exists, among other versions, as a self-report for parents and children aged $0-15$ years (Form P/PS). This version is to be used when interviewing the mother. With its 38 items, it measures her neglectful behavior when raising her child.
Furthermore, within the present study, a picture-based children's version is presented. The picture cards are thereby shown to the child, who chooses situations that are applicable to their everyday family life. The children are presented with the three scales emotional neglect, cognitive neglect and supervisory neglect.

\section{Research question 3: Maternal mental health Stress}

The short form of the Depression-Anxiety-Stress Scale (DASS-21 [70]; a translation adapted to the target group (forward-backward)) serves to assess the frequency (never to very often) of negative emotional states during the last 4 weeks. The DASS-21 contains three dimensions: depression (e.g., dysphoria and hopelessness, anxiety (e.g., autonomic arousal and situational anxiety) and stress (e.g., chronic, non-specific arousal and irritability).

\section{Psychopathology}

The DIA-X [51] is a fully structured diagnostic procedure to measure mental disorders based on ICD-10 and DSM-IV criteria. The interview is a modified form of the CIDI (Composite International Diagnostic Interview) from the World Health Organization (WHO). The DIA-X makes it possible to survey more than 100 mental disorder categories. It gathers data on organic mental disorders, substance disorders, affective disorders (manias, hypomanias, depressive disorders), anxiety disorders, obsessive-compulsive disorders, reactions, dissociative disorders, somatoform disorders and eating disorders. Lifetime as well as acute diagnoses can be obtained. The DIA-X is divided into 16 sections. Due to the possibility of selecting and presenting individual sections of the interview, an adapted interview that focuses on specific disorders can be carried out. The instrument comprises four DIA-X screening questionnaires: one stem screening questionnaire, which contains all 16 stem questions in the DIA-X interview, an anxiety screening questionnaire, a depression screening questionnaire, and a questionnaire regarding premenstrual syndrome. These questionnaires make it possible to assess whether it is any indication to conduct the entire DIA-X interview. The interrater reliabilities are specified as being between the values of Kappa $=.81$ to 1.0 .

\section{Social support}

The short form of the questionnaire regarding perceived social support (FSozU-K 6 [71]) measures the social support as perceived or anticipated support from the social environment. The items are in the form of statements, whereby the participant specifies their level of agreement on a 5-point scale (not at all true to absolutely true). The internal consistency of FSozU-K6 was found to be Cronbach's $\alpha=.90$. 


\section{Stress due to parenting tasks}

The Parenting Stress Index (PSI) [72] (German version: Eltern-Belastungs-Inventar, EBI [73]) assesses whether parents, due to an increased level of stress, are impaired regarding their care and support of their child. The EBI contains a total of 48 items that are answered on a 5-point Likert scale (absolutely true to not true at all). The internal consistency of the EBI overall scale amounts to Cronbach's $\alpha=.95$.

\section{Partnership}

\section{Partnership satisfaction}

The short form of the partnership questionnaire (PFB-K; $[74,75])$ assesses the satisfaction in a partnership or marriage with the help of nine items. Three items can be allocated to each of the three subscales fighting behavior, tenderness and commonality/communication. Within a representative population survey, an internal consistency of Cronbach's $\alpha=.84$ (women: Cronbach's $\alpha=.87$; men: Cronbach's $\alpha=.81$ ) was determined for the overall value of the PFB-K.

\section{Partnership violence}

The Conflict Tactics Scales (CTS2) [54] translation adapted to the target group (forward-backward)) serves to assess conflict resolution strategies within the family or close relationships. The CTS2 (revised and modified version of the CTS) measure three forms of conflict handling: negotiation (six items), psychological aggression (eight items) and physical violence (12 items). In addition, it measures sexual coercion (seven items) and injuries caused by violence by the partner (six items). With the help of CTS2, information is collected about one's own behavior as well as that of the partner. The latter is relevant to the present study.

\section{Partnership stability}

The items assessing partnership stability document the marital status of the participant (unmarried, married, widowed or divorced). Additionally, the participants are asked for household composition, whether she is in a partnership and whether the partner is the biological father of the treatment child.

\section{Self-efficacy}

The Parenting Sense of Competence Scale (PSOC [76] translation adapted to the target group [forward-backward]) measures the experience of competence in the role as parent on two dimensions: satisfaction and efficacy. The dimension satisfaction comprises nine items and includes parental care, motivation and frustration. The dimension efficacy measures parental competency, performance and problem-solving ability with the help of seven items. The 16 items are presented as statements and assessed on a six-point Likert scale (strongly disagree to strongly agree).

\section{Life satisfaction}

The German Version of the Life Satisfaction Questionnaire ("Fragebogen zur Lebenszufriedenheit", FLZ [77]) serves to measure relevant aspects of life satisfaction in ten areas of life (health, work and career, financial situation, recreation, marriage and partnership, relationship with one's children, own self, sexuality, friends/ acquaintances/ relatives and housing). Each subscale comprises seven items, which are assessed on a 7-point rating scale (very dissatisfied to very satisfied). The questionnaire can be used from the age of 14 and will be used when interviewing the mother. In addition to measuring the area-specific life satisfaction, the FLZ allows for the assessment of the general life satisfaction, which is calculated as the sum score of seven of the ten scales. The internal consistency for the overall value are satisfactory (mothers $\alpha=.74$; fathers: $\alpha=.76$ ). The FLZ was standardized via a representative German sample, hence norms are available for various age and occupational groups.

\section{Research question 4: The families' socio-economic situation Family income, employment and education}

Different scales from the German Socio-Economic Panel (SOEP) [49] were used to asses family income, employment rates and educational status. The German SOEP study (GSOEP) is conducted by the Deutsches Institut für Wirtschaftsforchung (DIW - German Institute for Economic Research). It was initiated in 1984 and has been conducted annually since then.

\section{Acceptance of employment, training or educational offers}

A five-item scale used in the SOEP [49] as well as in the Panel Labor Market and Social Security (PASS [78]) was used to measure employment attitudes. These questions contain certain statements about the importance of employment for the individual to which the participant can completely agree or completely disagree. Additionally, a six-item scale used in the SOEP and PASS assesses acceptable obstacles regarding the start of an occupation. The respondents can rate these difficulties on a 4-point Likert scale from I will accept in any case to I will not accept in any case.

\section{Welfare payments}

The Research Data Centre (FDZ) of the Federal Employment Agency at the Institute of Employment Research (IAB) provides social security data (Integrated Employment History) for all participants. The participating individuals will be identified by the participants' name, date of birth and address from the social security data. For all participants who are identified via their social security data, it is possible to merge survey and assessment data with their welfare receipt spells, amount of welfare, and 
additional cash transfers. Additionally, the social security data provides employment spells, wage spells and indicators about the type of occupation. The data is available from the participant's entry into the labor market until the time of the follow-up data collection.

\section{Family situation}

The Home Observation for Measurement of the Environment (HOME [59] forward-backward translation by the authors) assesses the lifestyle and living situation within a family. As an external evaluation, following the home-visiting, the interviewer reports whether, based on yes-no answers, certain circumstances (e.g., regarding the apartment) or behaviors (e.g., regarding the interaction with the child) could be observed in the family or not. Yes identifies the existence and No the non-existence of the circumstance or behaviors specified by each item. Depending on the age of the children, the HOME consists of 45 to 60 items. The subscales also vary depending on the version. The HOME exists in four versions for the assessment of the living situations of children of different age groups. Due to some questionable items (e.g., negative rating for the lack of a television), the items were culturally adapted to the German-speaking area as well as to family life in the 21st century in general.

\section{Research question 5: Health and health service utilization of mother and child \\ Mother's physical health}

The 12-item Short Form Health Survey (SF-12 [79]) is an outcome-oriented, subjective measure of physical and mental health. It includes 12 items. Ten items are assessed on a 5-point Likert scale asking how often (always to never) different physical and mental stresses and strains are absent or present in the previous 4 weeks. Additionally, two questions assess whether the health status decreases (strongly, a little bit, not at all) the ability to climb stairs and lift. Anderson et al. [79] show that the SF-12 is a suitable instrument to conduct health economic quality of life calculations. As the SF-12 is widely used in other panel surveys, it provides the possibility for external validation of the participant's responses.

\section{Child physical health and health service utilization}

The German Health Interview and Examination Survey for Children and Adolescents (KiGGS) questionnaire [80] assesses accidents which lead to outpatient or inpatient care in the last 12 months before the survey. In the case of an accident, the location and the type of the accident are inquired of, as well as the injury sustained. For all these questions standardized answers are presented. Furthermore, the KiGGS questionnaire inquires the frequency of certain diseases as well as the utilization of certain health care services. An alternative source for the assessment of pediatric primary care usage (e.g., screenings, vaccinations) is the evaluation of health insurance data. For those participants who declared consent, data can be merged to the participants by the individual health insurance number. With the help of the International Statistical Classification of Diseases and Related Health Problems (ICD) code, it is possible to identify the date and frequency of pediatric primary care utilization.

\section{Number of injuries}

The health insurance data can also be used to identify injuries that lead to a hospital admission or physician visit. All injuries and intoxications are coded $\mathrm{S}$ and $\mathrm{T}$ in the ICD systematic. Due to the health insurance data, it is possible to identify the date of the injury, the duration of treatment and which follow-up treatments are needed which can serve as a proxy for the severity of the injury.

\section{Data analysis}

The primary and secondary analyses will be conducted on an intention-to-treat basis. Multilevel modeling will be used for statistical analyses of our primary and secondary outcomes. Prior to analysis, data will be checked for outliers, inconsistencies and possible transformation. We predict that our sample size will be large enough for our statistical tests to be robust regarding non-normally distributed variables. To reduce bias and loss of statistical power in our analysis of primary and secondary outcome indicators, we will use multiple imputations to estimate values for missing data. Power analyses (i.e., sensitivity) based on an attrition rate of $30 \%(N=542$ for the CATIs, CAPIs and developmental tests) given a type I error rate (false positive) of $\alpha=.05$ and statistical power of $1-\beta=.80$ resulted in a minimum detectable effect sizes of $E S=0.2$. For an attrition rate of $40 \%(N=$ 465) a minimum detectable effect sizes of $E S=0.23$ was estimated. To take that into account we analyze different outcome measures within one hypothesis, we will adjust our results for multiple hypothesis testing (MHT) to control the family-wise type I error rate.

\section{Subgroup analysis}

We will conduct preplanned analyses for different participants' and child characteristics contributing to positive effects in the original trial (see [43, 45-47]). For this purpose, we consider the influence of different factors (i.e., maternal age at pre-assessment and number of mother-related risk factors at pre-assessment and child gender). Additionally, we will analyze subsequent births as a mediating factor of treatment efficacy in a preplanned subgroup analysis as a greater number of second births in the treatment group was a main effect in the original trial. Due to earlier findings [45], all primary and secondary 
outcomes will be analyzed with regard to any differential effects, while controlling for children's gender.

\section{Discussion}

The aim of the study is to conduct a follow-up survey regarding the effectiveness of the German adaptation of the NFP program, approximately 6 years after the intervention ended. The following variables are to be tested regarding the medium-term effectiveness of the home-visiting program: (1) prevention of mental and physical illnesses in mothers as well as children, (2) strengthening of parenting skills and prevention of child abuse and neglect, (3) improvement of child's cognitive development and school performance, (4) strengthening child's socio-emotional development, (5) positively influencing the socio-economic situation of the family, (6) positively influencing the psychosocial situation of the family and (7) reduction of the costs to the health and social system.

NFP's medium-term effectiveness has, however, not previously been tested in Europe. This poses a problem, not least because NFP constitutes a time-limited intervention that is implemented prenatally as well as over the first 2 years of the child's life. It should, however, be noted that findings from NFP trials in the US indicate that significant benefits can increase over time and that new developmental advantages may arise as the children grow older. As an example, many of the most conclusive findings regarding NFP have been found as late as 5 to 20 years after the end of the intervention. This includes a reduction in the child's level of anxiety, depression and substance abuse symptoms; a reduction in severe antisocial behavior during adolescence; and a decrease in both child and maternal mortality from preventable causes $[13,14,25]$. Due to these later occurring effects, a benefit-cost ratio greater than 1 does not emerge before age 5 years [32]. Bearing this in mind, this RCT was designed to allow for long-term follow-up - both through strong retention efforts and by including measures that predict the long-term outcome, such as the cognitive development and behavior of the child. This means that whatever successes or failures of NFP can be identified as a result of the outcome of trials conducted when children turn 2 years old, these findings may be invalidated during the children's subsequent periods of development.

\section{Limitations}

Selective data loss can lead to a skewed assessment of intervention effects. However, non-selective data loss also has adverse consequences, such as a decrease in the statistical power. In order to ensure maximum participation of the families who were contacted, a double-staged recruiting strategy is pursued: To obtain the missing contact data, in a first step, access is gained to data from the residents' registration offices and the employment agencies. In a second step, the successfully contacted families are offered financial incentives for a renewed participation in the study. Furthermore, contact with the participants was continuously maintained between project phases. For example, participants regularly received birthday and Christmas cards as part of panel maintenance.

\section{Implications}

Although studies from the US confirm the effectiveness of NFP, these results cannot simply be transferred to European countries. Overall high-quality replications (i.e., RCTs) of the US studies are scarce (with the exception of RTCs in the UK, France and The Netherlands). Especially for Germany, this seems problematic as here comprehensive support of comparable programs is provided with public funding (e.g., the Federal Government supported the "Netzwerk Frühe Hilfen" (National Center for Early Support) from 2012 to 2015 with up to $€ 177$ million), even though a comprehensive and long-term assessment of the corresponding programs has yet to be undertaken. In spite of a large number of early childhood interventions and special home-visiting programs with limited methodological quality in Germany [81], no medium-term RCT has been conducted to examine the effectiveness of home-visiting programs within the early childhood support in Germany.

\section{Ethical approval}

The Ethics Committee of the German Society for Psychology (DGPs; Registration No.: SK 122014), as well as the Ethics Committee of the University of Leipzig authorized the study's design and procedure (406-14-15,122,014). A data protection concept is available that received positive appraisal by the responsible data protection officer in Lower Saxony (2.2-1759-240). Participation in the interviews and the testing is voluntary. No disadvantages will result if the participant decides not to agree to an interview. Withdrawing from the study is possible at any time, verbally or in writing. If a participant withdraws her consent, all data that identify her are deleted and the remaining data concerning the participant will be processed anonymously. All participants will be informed in an appropriate form and in simple language about the results of the studies that are conducted. The project staff are available to answer any questions. Should there be any unusual findings, the participants will be supported in receiving counseling or other assistance for herself and her child.

\section{Dissemination}

After completion of data assessment, the anonymous data will be shared among the cooperating institutions. As further follow-ups are planned (up to the children's 20th birthdays), access to the data (including video- and audio-recordings, that will be blurred for alienation or 
deleted after evaluation) will remain limited to the scientist from the cooperating institutions. Dissemination of the results to the professional as well as the lay public is pursued by publications in peer-reviewed journals, project reports as well as with the help of the interdisciplinary network "Nationales Zentrum Frühe Hilfen (NZFH - National Center for Early Support)" which is an important platform for early childhood interventions and prevention in Germany. Results from the Pro Kind Follow-up will provide a scientific basis for future primary prevention programs as well as help stakeholders legitimizing early childhood investments.

\section{Trial status}

Collection and assessment of contact addresses began in September 2014. The first mothers have been contacted in October 2014 to assess their willingness to participate in the follow-up. The first telephone interviews have been held in April 2015. Data collection is expected to be completed by 31 December 2017.

\section{Endnotes}

${ }^{1}$ No odds ratio can be calculated because there was no event in the intervention group. The $p$-value is based on the relevant percentage points (linear model).

\section{Additional files}

Additional file 1: Standard Protocol Items: Recommendations for Interventional Trials (SPIRIT) Checklist. (PDF $169 \mathrm{~kb}$ )

Additional file 2: Model consent form. (PDF $503 \mathrm{~kb}$ )

\begin{abstract}
Abbreviations
AMIS: Analyzing pathways from childhood maltreatment to internalizing symptoms and disorders in children and adolescents; BMFSJ: German Federal Ministry for Family Affairs, Senior Citizens, Woman and Youth; BUEGA: Basic diagnostics of specific developmental disorders in elementary school children; CAPI: Computer-assisted personal interview; CATI: Computer-aided telephone interviews; CBCL: Child Behavior Checklist: CTS-CV: Conflict Tactic Scale; CTS-PC: Parent-Child Conflict Tactic Scales; DASS-21: Short form of the Depression-Anxiety-Stress Scale; DGPs: German Society for Psychology; DIW: German Institute for Economic Research; EBI: Eltern-Belastungs-Inventar; FAVK: German questionnaire for aggressive behavior in children; FDZ: Technical Data Center of the IAB; FLZ: German Version of the Life Satisfaction Questionnaire; FSozU-K 6: Short form of the questionnaire regarding social support; HOME: Home Observation for Measurement of the Environment; IAB: Institute for Employment Research; ICU: Inventory of Callous-Unemotional Traits; ILK: Inventar zur Erfassung der Lebensqualität bei Kindern und Jugendlichen; KFN: Criminological Research Institute of Lower Saxony; KiGGS: German Health Interview and Examination Survey for Children and Adolescents; Kinder-DIPS: Diagnostic Interview for Mental Disorders for Children and Adolescents; MNBS: Multidimensional Neglectful Behavior Scale; MNBS: Multidimensional Neglectful Behavior Scale; NFP: Nurse Family Partnership Program; NZFH: National Center for Early Support; PASS: Panel Labor Market and Social Security; PFB-K: Partnership questionnaire; PS: Parenting Scale; PSI: Parenting Stress Index; PSOC: Parenting Sense of Competence Scale; ROI: Return on investment; SF12: Short Form Health Survey; SOEP: German Socio-Economic Panel
\end{abstract}

\section{Acknowledgements}

We extend our gratitude to all members of staff of the Pro Kind Follow-up: Mona Bode, Ulrike Schoch, Vera Diekmann, Julia Finke, Ronja Wiesenmüller, Isabelle Deterding, Johanna Schlimpert, Sarah Kirchmann-Kallas, Sabrina Lauenroth, Ronja Ridder, Carolin Schimmele, Nancy Schwalenberg, Christina Trauth, Katharina Heermann, Katharina Hohmann, Isabel Schumann, Marie Püffel, Aline Debener, Julian Paffrath, Imke Bergmann, Lara Sophie Riewesell, Helena Wahl, Pia Spannagel, Nicola Jakobs, Ella Eidelmann, Linda Zimmermann, Alisa Carolin Tappert, Karen Husemann, Anne Tomm, Caro Schneider, Livia Kraft, Carina Sperk, Anna Henschel, Josefine Schulz, Peter Slomka, Maria Häberlein, Roula Jamous, Lina Winkler - as well as all the participating families whose cooperation enables this research.

\section{Funding}

The study is fully funded by the German Federal Ministry of Education and Research (BMBF funding codes: 01EL1408A, 01EL1408B, 01EL1408C). The funder was not and will not be involved in the design of the study, the collection, analysis and interpretation of data or the writing of the protocol.

\section{Availability of data and materials}

The datasets generated and/or analyzed during the current study are not publicly available as the participants did not consent to open accessibility of the data (see Additional file 1). Data is shared among the first and secondary sponsors for joint data analysis. Further information regarding data and stimulus material is available from the corresponding author upon reasonable request.

\section{Authors' contributions}

SK drafted the protocol. MS, SS, VD, AK, AL and TJ, revised the draft critically for important intellectual content and approved the final manuscript for submission. All authors read and approved the final manuscript.

\section{Authors' information}

SK is a senior researcher and head of the research unit "monitoring of unreported crime" at the Criminological Research Institute of Lower Saxony (KFN) in Hannover, Germany. He obtained his PhD from Brunswick University where he also held an interim professorship in the Department of Psychological Diagnostics and Psychotherapy. His research interests include parenting interventions, relationship quality, partner violence as well as questionnaire development and validation.

MS obtained a PhD in economics at Leibniz University Hannover. His work concentrates on the economic evaluation of early childhood interventions and other welfare policies. Additionally, he is interested in how these policies affect child development.

SS, PhD is a research associate at the Department of Medical Psychology and Medical Sociology and at the Department of Child and Adolescent Psychiatry, Psychotherapy, and Psychosomatics at the University of Leipzig. Her research area covers the topic of traumatization and psychopathology in children and adolescents. In her research projects, she evaluated the effectiveness of a German early intervention program for disadvantaged families, and analyzed biopsychosocial pathways from early maltreatment to internalizing symptoms and disorders. Currently, Dr. Sierau is conducting a study on the mental health of unaccompanied refugee children in Germany. VD, gained a diploma in psychology at the University of Leipzig in 2013. She used to be a student assistant at the Department of Child and Adolescent Psychiatry at the projects Pro Kind as well as "Analyzing pathways from childhood maltreatment to internalizing symptoms" (AMIS). Since 2013 she has been a PhD student at the Medical Faculty of the University of Leipzig and, since 2014, a research associate at the project Pro Kind Follow-up $\mathrm{AK}, \mathrm{PhD}$, is senior researcher and research coordinator at the Department of Child and Adolescent Psychiatry, Psychotherapy, and Psychosomatics at the University of Leipzig. Her research area covers trajectories of mental health problems in children and adolescents, early risk factors (e.g., parental psychopathology, life events, maltreatment experiences) and social-cognitive capacities.

$\mathrm{AL}$ is a research assistant at the criminological Research Institute of Lower Saxony. She obtained a Bachelor degree in Mathematics from the University of Hannover and a psychology degree from Hagen University. She is currently enrolled in the Graduate School of the Social and Behavioral Sciences at Utrecht University. 
TJ is a professor for language pathology and early development at the University of Rostock. She conducted post-doctoral research in the area of special needs psychology at the Leibniz University of Hanover. TJ obtained her psychology degree and PhD from the University of Bielefeld specializing in developmental psychology.

\section{Ethics approval and consent to participate}

The Ethics Committee of the German Society for Psychology (DGPs; Registration No.: SK 122014), as well as the Ethics Committee of the University of Leipzig authorized the study's design and procedure (Az:40614-15,122,014). Consent was obtained from all participants. Mothers furthermore provided parental consent prior to assessment of the children The original consent form as presented to the mother as well as to the child is attached in the file pro-kind_consent.pdf.

\section{Competing interests}

The authors declare that they have no competing interests.

\section{Publisher's Note}

Springer Nature remains neutral with regard to jurisdictional claims in published maps and institutional affiliations.

\section{Author details}

'Criminological Research Institute of Lower Saxony, Lützerodestr 9, 30161 Hannover, Germany. ${ }^{2}$ Institute for Employment Research (IAB) of the German Federal Employment Agency (BA), Regensburger Strasse 104, 90478 Nuremberg, Germany. ${ }^{3}$ Department of Medical Psychology and Medical Sociology, Universitätsklinikum Leipzig, Philipp-Rosenthal-Str. 55, 04103 Leipzig, Germany. ${ }^{4}$ Department of Child and Adolescent Psychiatry, Psychotherapy, and Psychosomatics, Cr, Liebigstraße 20a, 04103 Leipzig, Germany. ${ }^{5}$ Institut für Sonderpädagogische Entwicklungsförderung und Rehabilitation (ISER), August-Bebel-Str. 28, 18055 Rostock, Germany.

\section{Received: 10 September 2017 Accepted: 25 May 2018}

\section{Published online: 20 June 2018}

\section{References}

1. Mikton C, Butchart A. Child maltreatment prevention: a systematic review of reviews. Bull World Health Org. 2009;87:353-61. https://doi.org/10.2471/BLT. 08.057075 .

2. Peacock S, Konrad S, Watson E, Nickel D, Muhajarine N. Effectiveness of home visiting programs on child outcomes: a systematic review. BMC Public Health. 2013:13:17. https://doi.org/10.1186/1471-2458-13-17.

3. Sweet MA, Appelbaum MI. Is home visiting an effective strategy? A metaanalytic review of home visiting programs for families with young children Child Dev. 2004;75:1435-56. https://doi.org/10.1111/j.1467-8624.2004.00750.x

4. MacMillan HL, Wathen CN, Barlow J, Fergusson DM, Leventhal JM, Taussig $\mathrm{HN}$. Interventions to prevent child maltreatment and associated impairment. Lancet. 2009;373:250-66. https://doi.org/10.1016/S01406736(08)61708-0.

5. Bilukha O, Hahn RA, Crosby A, Fullilove MT, Liberman A, Moscicki E, et al. The effectiveness of early childhood home visitation in preventing violence: a systematic review. Am J Prev Med. 2005;28:11-39. https://doi.org/10.1016/ j.amepre.2004.10.004

6. Avellar SA, Supplee LH. Effectiveness of home visiting in improving child health and reducing child maltreatment. Pediatrics. 2013;132(Suppl 2):S90-9. https://doi.org/10.1542/peds.2013-1021G.

7. Kendrick D. Does home visiting improve parenting and the quality of the home environment?: a systematic review and meta analysis. Arch Dis Child. 2000;82:443-51. https://doi.org/10.1136/adc.82.6.443.

8. Euser S, Alink LR, Stoltenborgh M, Bakermans-Kranenburg MJ, van IJzendoorn MH. A gloomy picture: a meta-analysis of randomized controlled trials reveals disappointing effectiveness of programs aiming at preventing child maltreatment. BMC Public Health. 2015;15:1068. https://doi.org/10. 1186/s12889-015-2387-9.

9. Kamerman SB, Kahn AJ. Home health visiting in Europe. Future Child (Future Child). 1993;3:39. https://doi.org/10.2307/1602542.

10. Olds DL. The nurse-family partnership: an evidence-based preventive intervention. Infant Ment Health J. 2006;27(1):5-25. https://doi.org/10.1002/ imhj.20077.
11. Eckenrode J, Ganzel B, Henderson CR, Smith E, Olds DL, Powers J, et al. Preventing child abuse and neglect with a program of nurse home visitation: the limiting effects of domestic violence. JAMA. 2000;284:1385-91.

12. Eckenrode J, Campa M, Luckey DW, Henderson CR, Cole R, Kitzman H, et al. Long-term effects of prenatal and infancy nurse home visitation on the life course of youths: 19-year follow-up of a randomized trial. Arch Pediatr Adolesc Med. 2010;164:9-15. https://doi.org/10.1001/archpediatrics.2009.240.

13. Kitzman H, Olds DL, Henderson CR, Hanks C, Cole R, Tatelbaum R, et al. Effect of prenatal and infancy home visitation by nurses on pregnancy outcomes, childhood injuries and repeated childbearing. A randomized controlled trial. JAMA. 1997:278:644-52.

14. Kitzman H, Olds DL, Sidora K, Henderson CR, Hanks C, Cole R, et al. Enduring effects of nurse home visitation on maternal life course: a 3-year follow-up of a randomized trial. JAMA. 2000;283:1983-9.

15. Kitzman HJ, Olds DL, Cole RE, Hanks CA, Anson EA, Arcoleo KJ, et al. Enduring effects of prenatal and infancy home visiting by nurses on children: follow-up of a randomized trial among children at age 12 years. Arch Pediatr Adolesc Med. 2010;164:412-8. https://doi.org/10.1001/ archpediatrics.2010.76.

16. Olds D, Henderson CR, Cole R, Eckenrode J, Kitzman H, Luckey D, et al. Long-term effects of nurse home visitation on children's criminal and antisocial behavior: 15-year follow-up of a randomized controlled trial. JAMA. 1998;280:1238-44

17. Olds DL, Eckenrode J, Henderson CR, Kitzman H, Powers J, Cole R, et al. Long term effects of home visitation on maternal life course and child abuse and neglect. Fifteen-year follow-up of a randomized trial. JAMA. 1997;278:637-43.

18. Olds DL, Henderson CR, Chamberlin R, Tatelbaum R. Preventing child abuse and neglect: a randomized trial of nurse home visitation. Pediatrics. 1986;78:65-78.

19. Olds DL, Henderson CR, Kitzman H. Does prenatal and infancy nurse home visitation have enduring effects on qualities of parental caregiving and child health at 25 to 50 months of life? Pediatrics. 1994;93:89-98.

20. Olds DL, Kitzman H, Cole R, Robinson J, Sidora K, Luckey DW, et al. Effects of nurse home-visiting on maternal life course and child development: age 6 follow-up results of a randomized trial. Pediatrics. 2004;1 14:1550-9. https:// doi.org/10.1542/peds.2004-0962.

21. Olds DL, Kitzman H, Hanks C, Cole R, Anson E, Sidora-Arcoleo K, et al. Effects of nurse home visiting on maternal and child functioning: Age-9 follow-up of a randomized trial. Pediatrics. 2007;120:e832-45. https://doi.org/10.1542/ peds.2006-2111.

22. Olds DL, Kitzman H, Knudtson MD, Anson E, Smith JA, Cole R. Effect of home visiting by nurses on maternal and child mortality: results of a 2decade follow-up of a randomized clinical trial. JAMA Pediatr. 2014;168:8006. https://doi.org/10.1001/jamapediatrics.2014.472.

23. Olds DL, Kitzman HJ, Cole RE, Hanks CA, Arcoleo KJ, Anson EA, et al. Enduring effects of prenatal and infancy home visiting by nurses on maternal life course and government spending: follow-up of a randomized trial among children at age 12 years. Arch Pediatr Adolesc Med. 2010;164: 419-24. https://doi.org/10.1001/archpediatrics.2010.49.

24. Olds DL, Robinson J, O'Brien R, Luckey DW, Pettitt LM, Henderson CR, et al. Home visiting by paraprofessionals and by nurses: a randomized, controlled trial. Pediatrics. 2002;110:486-96.

25. Olds DL, Robinson J, Pettitt L, Luckey DW, Holmberg J, Ng RK, et al. Effects of home visits by paraprofessionals and by nurses: age 4 follow-up results of a randomized trial. Pediatrics. 2004;114:1560-8. https://doi.org/10.1542/ peds.2004-0961.

26. Zielinski DS, Eckenrode J, Olds DL. Nurse home visitation and the prevention of child maltreatment: impact on the timing of official reports. Dev Psychopathol. 2009;21:441-53. https://doi.org/10.1017/ S0954579409000248.

27. Eckenrode J, Ganzel B, Henderson JCR, Smith E, Olds DL, Powers J, et al. Preventing child abuse and neglect with a program of nurse home visitation. JAMA. 2000:284:1385. https://doi.org/10.1001/jama.284.11.1385.

28. Kitzman $\mathrm{H}$. Effect of prenatal and infancy home visitation by nurses on pregnancy outcomes, childhood injuries, and repeated childbearing. JAMA. 1997;278:644. https://doi.org/10.1001/jama.1997.03550080054039.

29. Kitzman H, Olds DL, Sidora K, Henderson JCR, Hanks C, Cole R, et al. Enduring effects of nurse home visitation on maternal life course. JAMA. 2000:283:1983. https://doi.org/10.1001/jama.283.15.1983.

30. Olds D, Henderson JCR, Cole R, Eckenrode J, Kitzman H, Luckey D, et al. Longterm effects of nurse home visitation on children's criminal and antisocial behavior. JAMA. 1998;280:1238. https://doi.org/10.1001/jama.280.14.1238. 
31. Miller TR. Projected outcomes of nurse-family partnership home visitation during 1996-2013. USA Prev Sci. 2015;16:765-77. https://doi.org/10.1007/ s11121-015-0572-9+

32. Karoly LA, Cannon JS, Kilburn MR. Early childhood interventions: proven results, future promise. Santa Monica: Rand; 2005.

33. Lee $\mathrm{S}$, Aos $\mathrm{S}$, Miller MG. Evidence-based programs to prevent children from entering and remaining in the child welfare system: benefits and costs for Washington. Olympia: Washington State Institute for Public Policy; 2008.

34. Olds DL, Henderson CR, Phelps C, Kitzman H, Hanks C. Effect of prenatal and infancy nurse home visitation on government spending. Med Care. 1993;31:155-74.

35. Jack SM, Sheehan D, Gonzalez A, MacMillan HL, Catherine N, Waddell C. British Columbia healthy connections project process evaluation: a mixed methods protocol to describe the implementation and delivery of the nurse-family partnership in Canada. BMC Nurs. 2015;14:47. https://doi.org/10. 1186/s12912-015-0097-3.

36. Tubach F, Greacen T, Saïas T, Dugravier R, Guedeney N, Ravaud P, et al. A home-visiting intervention targeting determinants of infant mental health: the study protocol for the CAPEDP randomized controlled trial in France. BMC Public Health. 2012;12:648. https://doi.org/10.1186/1471-2458-12-648.

37. Mejdoubi J, van den Heijkant SCCM, van Leerdam FJM, Crone M, Crijnen A, HiraSing RA. Effects of nurse home visitation on cigarette smoking, pregnancy outcomes and breastfeeding: a randomized controlled trial. Midwifery. 2014;30:688-95. https://doi.org/10.1016/j.midw.2013.08.006.

38. Mejdoubi J, van den Heijkant SCCM, van Leerdam FJM, Heymans MW, Crijnen A, HiraSing RA. The effect of VoorZorg, the Dutch nurse-family partnership, on child maltreatment and development: a randomized controlled trial. PLoS One. 2015;10:e0120182. https://doi.org/10.1371/journal.pone.0120182.

39. Mejdoubi J, van den Heijkant SCCM, van Leerdam FJM, Heymans MW, HiraSing RA, Crijnen AAM. Effect of nurse home visits vs. usual care on reducing intimate partner violence in young high-risk pregnant women: a randomized controlled trial. PLoS One. 2013;8:e78185. https://doi.org/10. 1371/journal.pone.0078185.

40. Robling M, Bekkers M-J, Bell K, Butler CC, Cannings-John R, Channon S, et al. Effectiveness of a nurse-led intensive home-visitation programme for first-time teenage mothers (building blocks): a pragmatic randomised controlled trial. Lancet. 2016:387:146-55. https://doi.org/10.1016/S0140-6736(15)00392-X

41. Prevention Research Center for Family and Child Health. Nurse-family partnership international program. 2014 http://www.ucdenver.edu/academics/ colleges/medicalschool/departments/pediatrics/research/programs/prc/ research/international/Pages/international.aspx. Accessed 23 Jun 2017.

42. Brand T, Jungmann T. Implementation differences of two staffing models in the German home-visiting program Pro-Kind. J Community Psychol. 2012; 40:891-905. https://doi.org/10.1002/jcop.21489.

43. Sierau S, Dähne $V$, Brand $T$, Kurtz $V$, von Klitzing $K$, Jungmann $T$. Effects of home visitation on maternal competencies, family environment, and child development: a randomized controlled trial. Prev Sci. 2016;17:40-51. https:// doi.org/10.1007/s11121-015-0573-8.

44. Brand T, Jungmann T. Participant characteristics and process variables predict attrition from a home-based early intervention program. Early Child Res Q. 2014;29:155-67. https://doi.org/10.1016/j.ecresq.2013.12.001.

45. Sandner M, Jungmann T. Gender-specific effects of early childhood intervention: evidence from a randomized controlled trial. Labour Econ. 2017:59-78.

46. Sandner M. Effects of early childhood intervention on fertility and maternal employment: Evidence from a randomized controlled trial. University of Chicago: HCEO Working Paper.-74; 2017.

47. Sandner $M$, Cornelissen $T$, Jungmann $T$, Herrmann P. Evaluating the effects of a home visiting programme for at-risk mothers during pregnancy on mother and child health outcomes. J Health Econ. 2018;58:269-83.

48. Meier-Pfeiffer A, Kutz K, Kosten SM. Nutzen und Finanzierung der Frühen Hilfen. In: Brand T, Jungmann T, editors. Kinder schützen, Familien stärken. Erfahrungen und Empfehlungen für die Ausgestaltung Früher Hilfen aus der Pro Kind Praxis und -Forschung. Weinheim: Beltz Juventa; 2013. p. 111-24.

49. Siedler T, Schupp J, Spiess CK, Wagner GG. The German socio-economic panel (SOEP) as reference data set. Schmollers Jahr. 2009:367-74.

50. Kamtsiuris $P$, Lange $M$, Schaffrath Rosario A. Der Kinder- und Jugendgesundheitssurvey (KiGGS): Stichprobendesign, Response und Nonresponse-Analyse. Bundesgesundheitsblatt Gesundheitsforschung Gesundheitsschutz. 2007;50:547-56. https://doi.org/10.1007/s00103-007-0215-9.

51. Wittchen $\mathrm{H}-\mathrm{U}$, Lachner $\mathrm{G}$, Wunderlich $U$, Pfister $\mathrm{H}$. Test-retest reliability of the computerized DSM-IV version of the Munich-composite international diagnostic interview (M-CIDI). Soc Psychiatry Psychiatr Epidemiol. 1998;33: 568-78. https://doi.org/10.1007/s001270050095.

52. Schneider S, Margraf J. DIPS: Diagnostisches Interview bei psychischen Störungen. 4th ed. Berlin: Springer-Verlag Berlin Heidelberg; 2011.

53. Kantor GK, Holt MK, Mebert CJ, Straus MA, Drach KM, Ricci LR, et al. Development and preliminary psychometric properties of the multidimensional neglectful behavior scale-child report. Child Maltreat. 2004;9:409-28. https://doi.org/10.1177/1077559504269530.

54. Straus MA, Hamby SL, Boney-McCoy SUE, Sugarman DB. The revised conflict tactics scales (CTS2). J Fam Issues. 1996;17:283-316. https://doi.org/10.1177/ 019251396017003001.

55. Esser G, Wyschkon A, Balaschk K. BUEGA Basisdiagnostik Umschriebener Entwicklungsstörungen im Grundschulalter. Göttingen: Hogrefe; 2008.

56. Dohmen T, Falk A, Huffman D, Sunde U, Schupp J, Wagner GG. Individual risk attitudes: Measurement, determinants, and behavioral consequences. J Eur Econ Assoc. 2011;9:522-50. https://doi.org/10.1111/j.1542-4774.2011.01015.x.

57. Fehr E, Bernhard $H$, Rockenbach B. Egalitarianism in young children. Nature. 2008;454:1079-83. https://doi.org/10.1038/nature07155;

58. Mischel W, Shoda Y, Rodriguez M. Delay of gratification in children. Science. 1989;244:933-8. https://doi.org/10.1126/science.2658056.

59. Bradley $\mathrm{RH}$, Caldwell BM, Rock SL, Hamrick HM, Harris P. Home observation for measurement of the environment: development of a home inventory for use with families having children 6 to 10 years old. Contemp Educ Psychol. 1988;13:58-71. https://doi.org/10.1016/0361-476X(88)90006-9.

60. Achenbach TM, Rescorla LA. Manual for ASEBA school-age forms and profiles. Burlington: University of Vermont, Research Center for Children, Youth, and Families; 2001.

61. Döpfner M, Plück J, Kinnen C, Arbeitsgruppe Deutsche Child Behavior Checklist CBCL Handbuch-Schulalter. Manual zum Elternfragebogen über das Verhalten von Kindern und Jugendlichen. (CBCL/6-18R), zum Lehrerfragebogen über das Verhalten von Kindern und Jugendlichen (TRF/6-18R) und zum Fragebogen für Jugendliche (YSR/11-18R). Göttingen: Hogrefe; 2014.

62. Elliot SN, Gresham FM. Social skills improvement system. Minneapolis: Pearson Assessments; 2008

63. Görtz-Dorten A, Döpfner M. Fragebogen zum aggressiven Verhalten von Kindern. Göttingen: Hogrefe; 2010.

64. Essau CA, Sasagawa S, Frick PJ. Callous-unemotional traits in a community sample of adolescents. Assessment. 2006;13:454-69. https://doi.org/10.1177/ 1073191106287354.

65. Mattejat F, Remschmidt H. ILK: Inventar zur Erfassung der Lebensqualität bei Kindern und Jugendlichen. München: Huber; 2006.

66. Arnold DS, O'Leary SG, Wolff LS, Acker MM. The parenting scale: a measure of dysfunctional parenting in discipline situations. Psychol Assess. 1993;5: 137-44. https://doi.org/10.1037/1040-3590.5.2.137.

67. Straus MA, Hamby SL, Finkelhor D, Moore DW, Runyan D. Identification of child maltreatment with the parent-child conflict tactics scales: development and psychometric data for a National Sample of American parents. Child Abuse Negl. 1998;22:249-70. https://doi.org/10.1016/S0145-2134(97)00174-9.

68. Sierau S, White LO, Klein AM, Klitzing K von, Herzberg PY. Assessing physical abuse from children's perspective: Factor structure, measurement invariance, and validity of the Child-report Abusive Parenting Scales (CAPS). submitted for publication; 2017.

69. Straus MA, Kinard EM, Williams LM. The multidimensional neglectful behavior scale, Form A: Adolescent and adult-recall version. 1995. https:// www.researchgate.net/publication/228920879_The_multidimensional_ neglectful_behavior_scale_Form_A_Adolescent_and_adult-recall_version.

70. Lovibond PF, Lovibond SH. The structure of negative emotional states: comparison of the depression anxiety stress scales (DASS) with the Beck depression and anxiety inventories. Behav Res Ther. 1995;33:335-43. https:// doi.org/10.1016/0005-7967(94)00075-U.

71. Kliem S, Mößle T, Rehbein F, Hellmann DF, Zenger M, Brähler E. A brief form of the perceived social support questionnaire (F-SozU) was developed, validated, and standardized. J Clin Epidemiol. 2015;68:551-62. https://doi. org/10.1016/j.jclinepi.2014.11.003.

72. Abidin RR. Parenting stress index (PSI). Charlottesville: Pediatric Psychology Press; 1990.

73. Tröster H. Eltern-Belastungs-Inventar: EBl; deutsche Version des Parenting Stress Index (PSI) von RR Abidin. Göttingen: Hogrefe; 2011.

74. Kliem S, Job A-K, Kröger C, Bodenmann G, Stöbel-Richter Y, Hahlweg K, Brähler E. Entwicklung und Normierung einer Kurzform des Partnerschaftsfragebogens (PFB-K) an einer repräsentativen deutschen 
Stichprobe. Z Klin Psychol Psychother. 2012;41:81-9. https://doi.org/10.1026/ 1616-3443/a000135.

75. Kliem S, Foran HM, Beller J, Hahlweg K, Stöbel-Richter Y, Brähler E. Dimensional latent structure of relationship quality: results of three representative population samples. Fam Relat. 2015;77:1190-201. https://doi. org/10.1111/jomf.12211.

76. Ohan JL, Leung DW, Johnston C. The parenting sense of competence scale: evidence of a stable factor structure and validity. Can J Behav Sci. 2000;32: 251-61. https://doi.org/10.1037/h0087122.

77. Fahrenberg J, Myrtek M, Schumacher J. Fragebogen zur Lebenszufriedenheit (FLZ)Handanweisung, Fragebogen, Auswertungsbogen. Göttingen: Hogrefe; 2000

78. Trappmann M, Gundert S, Wenzig C, Gebhardt D. PASS-A household panel survey for research on unemployment and poverty. Schmollers Jahr. 2010; 130:609-22.

79. Andersen HH, Mühlbacher A, Nübling M, Schupp J, Wagner GG.

Computation of standard values for physical and mental health scale scores using the SOEP version of SF-12. Schmollers Jahr. 2007:127(1):171-82.

80. Kurth B-M. Der Kinder- und Jugendgesundheitssurvey (KiGGS): Ein Überblick über Planung, Durchführung und Ergebnisse unter Berücksichtigung von Aspekten eines Qualitätsmanagements. Bundesgesundheitsblatt Gesundheitsforschung Gesundheitsschutz. 2007;50:533-46. https://doi.org/ 10.1007/s00103-007-0214-x

81. Taubner S, Munder T, Unger A, Wolter S. Zur Wirksamkeit präventiver Früher Hilfen in Deutschland - ein systematisches Review und eine Metaanalyse. Prax Kinderpsychol Kinderpsychiatr. 2013;62:598-619. https://doi.org/10. 13109/prkk.2013.62.8.598

Ready to submit your research? Choose BMC and benefit from:

- fast, convenient online submission

- thorough peer review by experienced researchers in your field

- rapid publication on acceptance

- support for research data, including large and complex data types

- gold Open Access which fosters wider collaboration and increased citations

- maximum visibility for your research: over $100 \mathrm{M}$ website views per year

At BMC, research is always in progress.

Learn more biomedcentral.com/submissions 